\title{
Development and Verification of a Fully Coupled Simulator for Offshore Wind Turbines
}

Conference Paper NREL/CP-500-40979 January 2007

\section{Preprint}

J. M. Jonkman and M. L. Buhl, Jr.

To be presented at the $45^{\text {th }}$ AIAA Aerospace Sciences Meeting and Exhibit, Wind Energy Symposium

Reno, Nevada

January 8-11, 2007 


\section{NOTICE}

The submitted manuscript has been offered by an employee of the Midwest Research Institute (MRI), a contractor of the US Government under Contract No. DE-AC36-99G010337. Accordingly, the US Government and MRI retain a nonexclusive royalty-free license to publish or reproduce the published form of this contribution, or allow others to do so, for US Government purposes.

This report was prepared as an account of work sponsored by an agency of the United States government. Neither the United States government nor any agency thereof, nor any of their employees, makes any warranty, express or implied, or assumes any legal liability or responsibility for the accuracy, completeness, or usefulness of any information, apparatus, product, or process disclosed, or represents that its use would not infringe privately owned rights. Reference herein to any specific commercial product, process, or service by trade name, trademark, manufacturer, or otherwise does not necessarily constitute or imply its endorsement, recommendation, or favoring by the United States government or any agency thereof. The views and opinions of authors expressed herein do not necessarily state or reflect those of the United States government or any agency thereof.

Available electronically at http://www.osti.gov/bridge

Available for a processing fee to U.S. Department of Energy and its contractors, in paper, from:

U.S. Department of Energy

Office of Scientific and Technical Information

P.O. Box 62

Oak Ridge, TN 37831-0062

phone: 865.576 .8401

fax: 865.576 .5728

email: mailto:reports@adonis.osti.gov

Available for sale to the public, in paper, from:

U.S. Department of Commerce

National Technical Information Service

5285 Port Royal Road

Springfield, VA 22161

phone: 800.553 .6847

fax: 703.605.6900

email: orders@ntis.fedworld.gov

online ordering: http://www.ntis.gov/ordering.htm 


\title{
Development and Verification of a Fully Coupled Simulator for Offshore Wind Turbines"
}

\author{
Jason M. Jonkman ${ }^{\dagger}$ and Marshall L. Buhl Jr. ${ }^{\ddagger}$ \\ National Renewable Energy Laboratory (NREL), Golden, Colorado, 80401-3393
}

\begin{abstract}
The vast deepwater wind resource represents a potential to use floating offshore wind turbines to power much of the world with renewable energy. Comprehensive simulation tools that account for the coupled excitation and response of the complete system, including the influences of wind-inflow, aerodynamics, structural dynamics, controls, and, for offshore systems, waves, currents, and hydrodynamics, are used to design and analyze wind turbines. Continuing our work presented previously, we outline the development of such an analysis tool for floating offshore wind turbines, including a recently added, quasi-static mooring system module. The fully coupled simulator was developed with enough sophistication to address the limitations of previous frequency and time domain studies and to have the features required to perform an integrated loads analysis. It is also universal enough to analyze a variety of wind turbine, support platform, and mooring system configurations. The simulation capability was tested by model-to-model comparisons to ensure its correctness. The results of all of the verification exercises are favorable and give us confidence to pursue more thorough investigations into the behavior of floating offshore wind turbines. Some of the potential challenges to their design are highlighted through sample response simulations.
\end{abstract}

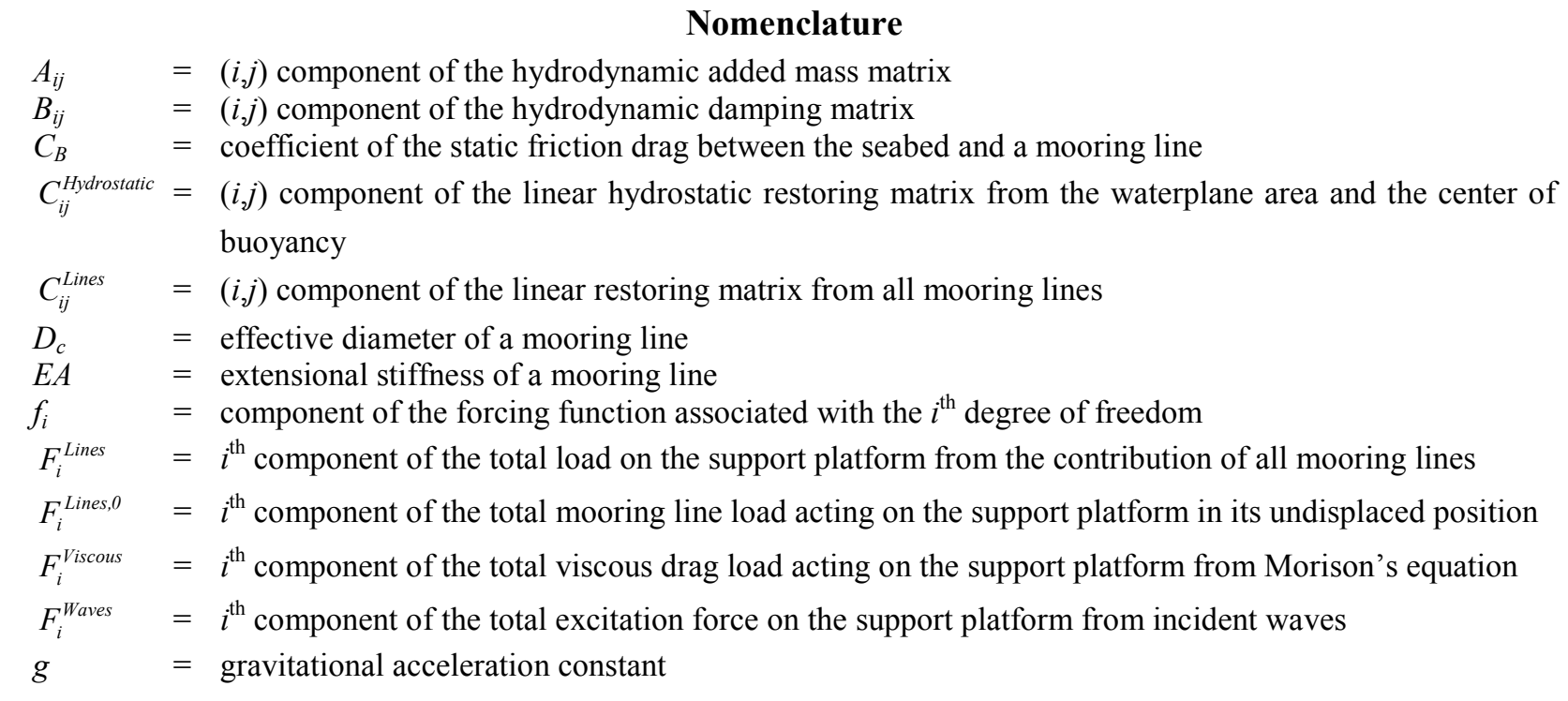

* Employees of the Midwest Research Institute under Contract No. DE-AC36-99GO10337 with the U.S. Dept. of Energy have authored this work. The United States Government retains, and the publisher, by accepting the article for publication, acknowledges that the United States Government retains a non-exclusive, paid-up, irrevocable, worldwide license to publish or reproduce the published form of this work, or allow others to do so, for the United States Government purposes.

${ }^{\dagger}$ Engineer II-Structural Systems \& Dynamics, National Wind Technology Center (NWTC), 1617 Cole Boulevard, AIAA Professional Member.

* Senior Engineer II-Structural Systems \& Dynamics, National Wind Technology Center (NWTC), 1617 Cole Boulevard, AIAA Professional Member. 


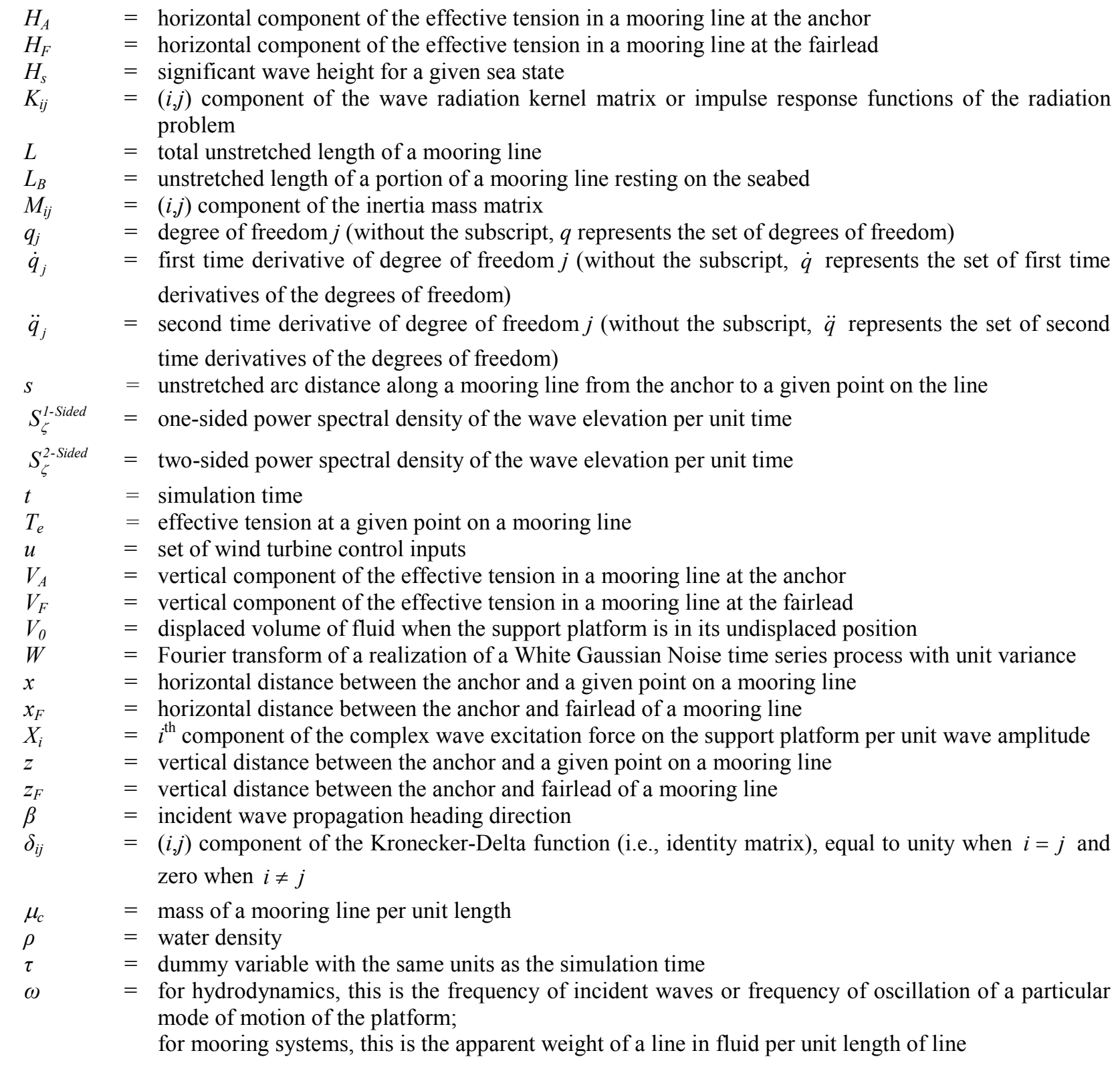

\section{Introduction}

T Europe, where vacant land is scarce and vast shallow water wind resources are available, more than $800 \mathrm{MW}$ of offshore wind energy capacity has been installed in and around the North and Baltic Seas. Although offshore wind turbines are not currently installed outside Europe, interest is growing worldwide, because the global offshore wind resource is abundant, with the U.S. potential ranked second only to China. For instance, the wind resource potential at 5 to 50 nautical miles off the U.S. coast is estimated to be more than the total currently installed electrical generating capacity of the United States (more than $900 \mathrm{GW}$ ).

Most of the offshore wind resource potential in the United States, China, Japan, Norway, and many other countries is available in water deeper than $30 \mathrm{~m}$. In contrast, most of the European offshore wind turbines installed to date are fixed-bottom and have been installed in water shallower than $20 \mathrm{~m}$ by driving monopiles into the seabed or by relying on conventional concrete gravity bases. These technologies are economically infeasible in deeper waters. Instead, space frame substructures, including tripods, quadpods, or lattice frames (Jackets), will be required to maintain the strength and stiffness requirements at the lowest possible cost. The Beatrice Wind Farm Demonstrator Project, where two 5-MW wind turbines will be installed on a Jacket in $45 \mathrm{~m}$ of water, is a good 
example of this technology. ${ }^{\S}$ At some depth, however, floating support platforms will be the most economical. Without performing a dynamic analysis, Musial, Butterfield, and Boone have demonstrated the economic potential of one floating platform design. ${ }^{2}$

Numerous floating support platform configurations are possible for offshore wind turbines when one considers the variety of mooring systems, tanks, and ballast options that are used in the offshore oil and gas industries. Figure 1 illustrates several of the concepts, which are classified in terms of how the designs achieve static stability. The Spar-buoy concept achieves stability by using ballast to lower the center of gravity below the center of buoyancy and can be moored by catenary or taut lines. The Tension Leg Platform (TLP) achieves stability through the use of mooring line tension brought about by excess buoyancy in the tank. The barge concept achieves stability through its waterplane area and is generally moored by catenary lines. Hybrid concepts, which use features from all three classes, are also an option. ${ }^{5}$

Numerous recent studies have assessed the preliminary design of floating offshore wind turbines. Many of these projects used linear frequency domain analysis, which is commonly employed in the offshore oil and gas industry. For example, Bulder et al used linear frequency domain hydrodynamics techniques to find the Response Amplitude Operators (RAOs) and amplitude standard deviations of the six rigid-body modes of motion for the support platform of a tri-floater design for a 5-MW wind turbine. A similar process was used by Lee to analyze a TLP design and a taut-leg Spar-buoy design for 1.5-MW wind turbine and by Wayman et al ${ }^{8,9}$ to analyze multiple TLP designs and a shallow drafted barge design for a 5-MW wind turbine. Most recently, through frequency domain analysis, Vijfhuizen designed a barge for a 5-MW wind turbine, which is also a platform for an oscillating water column (OWC) wave-energy device. In these studies, the attributes of the wind turbine were included by augmenting the body mass matrix with the mass properties of the turbine and by augmenting the hydrodynamic damping and restoring matrices with damping and restoring contributions from rotor aerodynamics and gyroscopics.

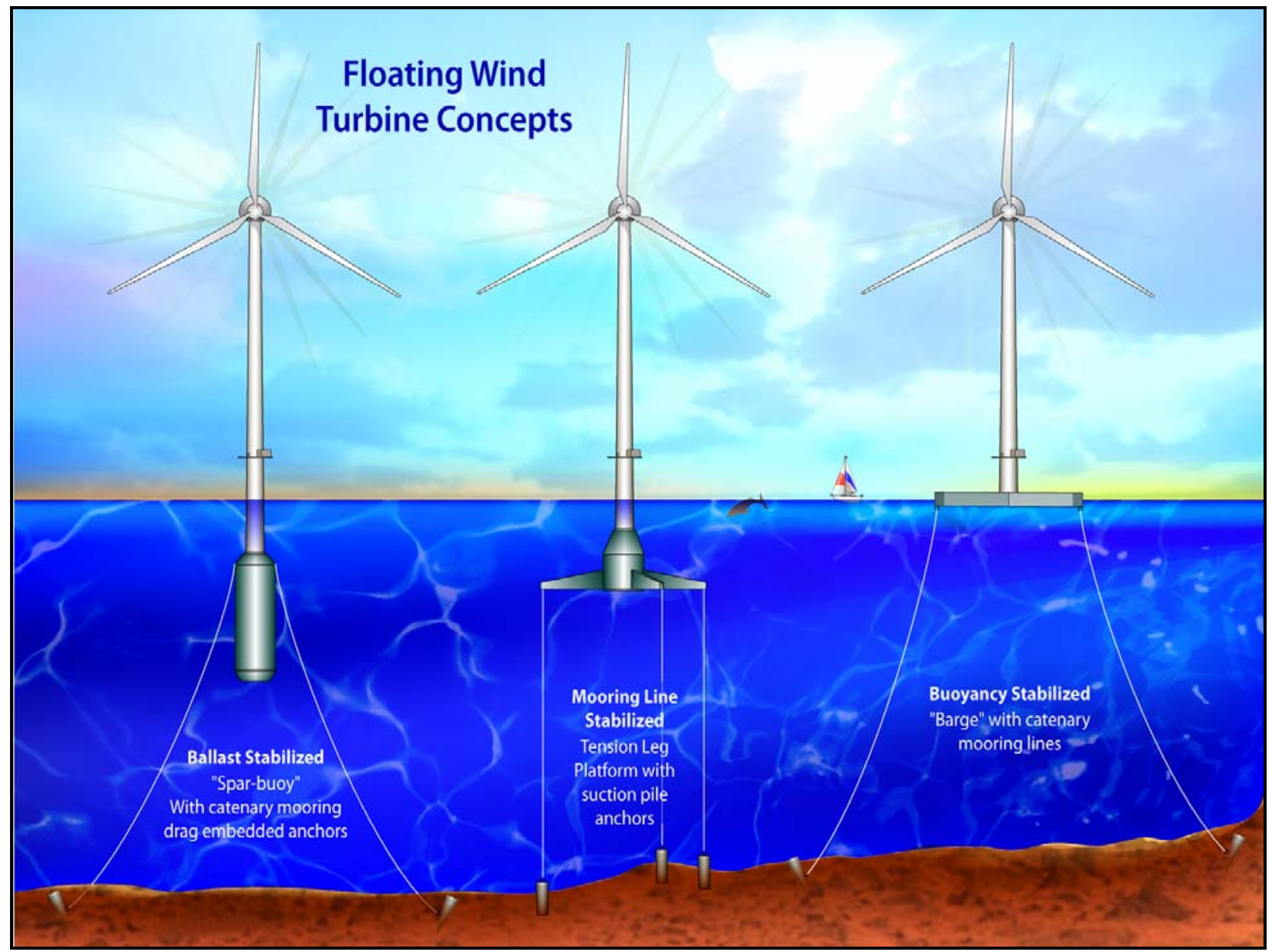

Figure 1. Floating support platform concepts for offshore wind turbines.

\footnotetext{
${ }^{\S}$ Website: http://www.beatricewind.co.uk/home/default.asp.
} 
Additionally, the linearized restoring properties of the mooring system were derived about a mean offset displacement of the support platform caused by the aerodynamic thrust on the rotor. The elasticity of the wind turbine was ignored. Bulder et al, Lee, Wayman et al, and Vijfhuizen all demonstrated the technical feasibility of floating offshore wind turbines by showing that, through proper design, the natural frequencies of the floating support platform could be placed where there is little energy in the wave spectrum to ensure that the dynamic response is minimized.

One limitation of these linear frequency domain analyses is that they cannot capture nonlinear dynamic characteristics and transient events that are important considerations in the analysis of wind turbines. Several floating offshore wind turbine studies have addressed this limitation. Using a state-domain technique, Henderson and Patel used RAOs to prescribe the motions of a $700-\mathrm{kW}$ wind turbine to determine the effect platform motions have on turbine fatigue loads. They showed that platform motions have little effect on power capture and rotor loads; instead, these are dominated by the aerodynamics of the rotor. However, they also showed that platform motions have a substantial effect on the nacelle and tower loads, which are dominated by inertia; thus, the tower will have to be strengthened if the platform motions cannot be reduced. The same conclusions were drawn independently by Fulton et al and Withee, who used different time-domain aeroelastic wind turbine simulators that had been adapted to include the effects of platform motion and hydrodynamic loading of TLP designs for a 5-MW and 1.5-MW wind turbine, respectively.

Limitations in these studies must also be addressed. For instance, the time domain dynamic models employed by Fulton et al and Withee used Morison's equation ${ }^{14,15}$ to compute of the hydrodynamic loading on the TLPs. Morison's equation ignores many of the effects that are important to the analysis of more general support platform configurations, such as the effects of platform size in the diffraction problem, wave radiation damping and freesurface memory, and added mass-induced coupling between modes of motion. ${ }^{16,17}$ Also, the conclusions drawn by Henderson and Patel, Fulton et al, and Withee must be verified through a rigorous loads analysis.

International design standards for wind turbines ${ }^{18,19}$ require that an integrated loads analysis be performed when a machine is certified. Such analysis is also beneficial for design, to obtain cost-effective wind turbines that achieve favorable performance and maintain structural integrity. Integrated loads analyses are carried out with comprehensive time-domain simulation tools that employ sophisticated models of both turbulent and deterministic wind-inflow; aerodynamic, gravitational, and inertial loading of the rotor, nacelle, and tower; elastic effects within and between components and in the foundation; and mechanical actuation and electrical responses of the generator and of the control and protection systems. For offshore wind turbines, additional models of the hydrodynamic loading in regular and irregular seas, the dynamic coupling between the support platform motions and wind turbine motions, and the dynamic characterization of mooring systems for compliant floating platforms are also necessary.

This paper is a continuation of the work presented previously by Jonkman and Sclavounos, which introduces the development of a comprehensive simulation tool that can model the fully coupled aero-hydro-servo-elastic response of floating offshore wind turbines. Our floating offshore wind turbine simulator was developed with enough sophistication to address the limitations of the previous time and frequency domain studies and to have the features required to perform an integrated loads analysis. A summary of the model development presented in, as well some corrections to, Ref. 20 are given in section II. We then present a verification of the simulation capability and demonstrate its potential in loads analysis applications. The results of comprehensive loads analyses will be presented in future papers.

\section{Development of a Fully Coupled Simulation Tool}

Although some wind turbine simulators have been expanded to include the additional loading and responses representative of fixed-bottom offshore support structures, ${ }^{21-26}$ only recently has simulation capability for modeling the fully coupled aero-hydro-servo-elastic response of floating offshore wind turbines been available. ${ }^{20}$ This simulation capability for floating offshore wind turbines has been developed by interfacing the hydrodynamic computer model WAMIT ${ }^{\circledR}$, which is commonly employed in the offshore oil and gas industry, with the wind industry-accepted aerodynamics module AeroDyn and servo-elastic simulation tools FAST and MSC.ADAMS ${ }^{\circledR}$. 30,31

A rundown of the interface and calculations is given in Fig. 2. See Ref. 20 for a detailed description of these calculations and nomenclature. To summarize, the aero-servo-elastic models of FAST and ADAMS with AeroDyn contain contributions from wind-inflow, aerodynamics, gravity, controls, and the structural dynamics of the wind turbine. This includes elasticity and the dynamic coupling between the motions of the support platform and the motions of the wind turbine. The nonlinear restoring loads from the mooring system were obtained by interfacing FAST and ADAMS with a quasi-static mooring line module that accounts for the elastic stretching of an array of homogenous taut or slack catenary lines with seabed interaction. The hydrodynamic loads on the support platform 


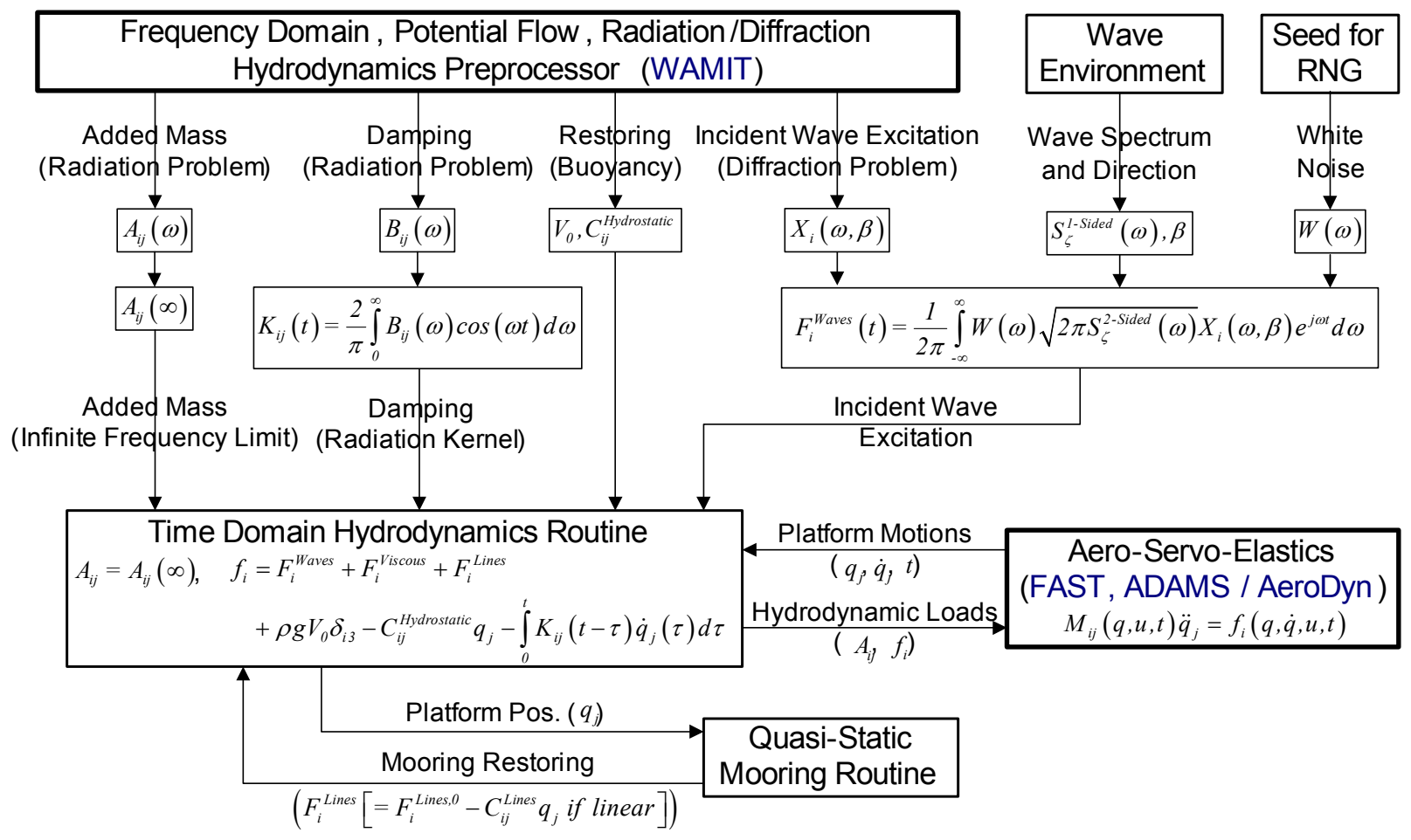

Figure 2. Summary of the calculations for the interface of support platform loads to FAST and ADAMS.

include the restoring contributions of buoyancy and the waterplane area from hydrostatics; the viscous drag contributions from Morison's equation; the added mass and damping contributions from wave radiation, including free surface memory effects; and the incident wave excitation from diffraction in regular or irregular seas. The matrices in the hydrodynamic loading expressions depend on the geometry of the support platform and can be found from the solution of the frequency domain, potential flow, radiation/diffraction, hydrodynamics problem ${ }^{14,15}$ by using WAMIT as a preprocessor. Not included in the model were the effects of mooring system inertia and damping, vortex-induced vibration and loading from sea ice, or nonlinear hydrodynamic effects, such as mean drift, slow-drift, and sum-frequency excitation and high-order wave kinematics. Reference 20 explains the model features and limitations in detail.

Three corrections to the information presented in Ref. 20 are noted. First, all the inverse Fourier transforms presented in Ref. 20 had the wrong sign in the exponent of the complex exponential. That is, the inverse Fourier transforms stated with $e^{-j \omega t}$ should have employed $e^{j \omega t}$ instead. Second, sea current has been introduced in the model, contrary to the assumption that is declared in the paper. To include the effects of sea current generated by winds, tides, and thermal gradients, the steady, depth-varying current velocity has been combined vectorally with the wave-particle velocity to compute the viscous-drag term from Morison's equation. The ancillary effect of the sea current on the radiation and diffraction problems, such as the Doppler-shifted frequency-of-encounter effect, ${ }^{15}$ is ignored. The third correction has to do with the treatment of the mooring system. Reference 20 proposed including mooring system behavior into the fully coupled model by interfacing the dynamic mooring system LINES module of SML ${ }^{32-35}$ with FAST and ADAMS. A quasi-static model of the mooring system has replaced this interface because it was discovered that LINES is numerically unstable when modeling the slack catenary lines of interest in our analyses. The development of this quasi-static mooring system module is presented next.

\section{A. Quasi-Static Mooring System Module}

Because we discovered that LINES was unsuitable for our use, we developed our own quasi-static module to simulate the nonlinear restoring loads from the mooring system of floating platforms. Instead of interfacing LINES, we have interfaced our mooring system module to FAST and ADAMS.

Our module can model an array of homogenous taut or slack catenary mooring lines. Our module accounts for the apparent weight in fluid, elastic stretching, and seabed friction of each line. And since our quasi-static module is fully coupled with FAST and ADAMS, the nonlinear geometric restoration of the complete mooring system is also 
accounted for. By quasi-static, we mean that with the fairlead positions known for a given platform displacement at any instant in time, our mooring system module solves for the tensions within, and configuration of, each mooring line by assuming that each cable is in static equilibrium at that instant. Using the tensions (and additional loading on the platform from hydrodynamics and loading on the turbine from aerodynamics), FAST or ADAMS solve the dynamic equations of motion for the accelerations of the rest of the system (platform, tower, nacelle, blades), then integrate in time to obtain new platform and fairlead positions at the next time step. (The process repeats at each time step.) Our model neglects the bending stiffness of the mooring lines.

Obviously, this quasi-static approach also ignores the inertia and damping of the mooring system, which may or may not be important in various situations. To justify the use of this approach, we used the system mass data presented in section III to calculate that the mass of a typical mooring system is eight percent of the combined mass of a typical wind turbine and floating support platform. According to our conversations with Dr. Robert Zueck of the Naval Civil Engineering Laboratory, about one-quarter of the inertia of a mooring system is important to the dynamic response of a floating platform. One-quarter of eight percent is only two percent, which justifies ignoring mooring system inertia in our analyses for these turbine/platform configurations. Also, ignoring mooring system damping is conservative.

A layout of the calculations in our quasi-static mooring system module is presented in Fig. 3. Each line of the mooring system is analyzed separately. The user must specify the fairlead locations of each mooring line relative (and fixed) to the support platform and the anchor locations of each mooring line relative (and fixed) to the inertia frame. For each mooring line, the total unstretched length, $L$, apparent weight in fluid per unit length, $\omega$, extensional stiffness, $E A$, and coefficient of seabed static friction drag, $C_{B}$, must also be assigned. Because a mooring line is buoyant, $\omega$ is related to the mass of the line per unit length, $\mu_{c}$, by:

$$
\omega=\left(\mu_{c}-\rho \frac{\pi D_{c}^{2}}{4}\right) g,
$$

where $\rho$ is the water density, $g$ is the gravitational acceleration constant, and $D_{c}$ is the effective diameter of the mooring line. Since we are limited to modeling homogenous mooring lines, we handle multi-segment lines (i.e. chain + wire + chain segments in series) by using an equivalent line with weighted average values of the weight and stiffness (weighted based on the unstretched lengths of each segment).

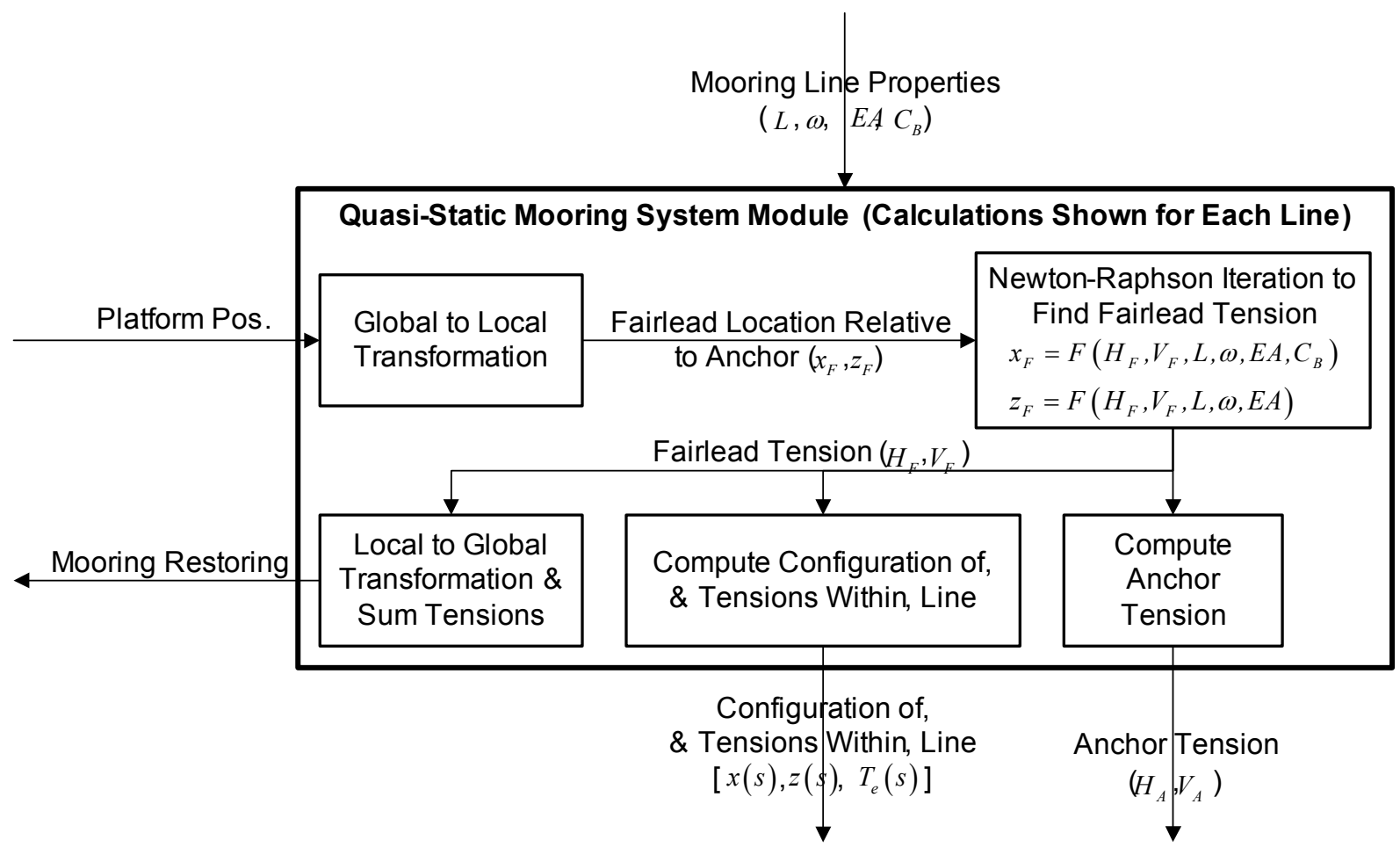

Figure 3. Summary of the calculations in our quasi-static mooring system module. 
Each mooring line is analyzed in a local coordinate system whose origin lies at the anchor. The local $z$ axis of this coordinate system is vertical and the local $x$-axis is directed horizontally from the anchor to the instantaneous position of the fairlead. Figure 4 illustrates a typical line. When the mooring system module is called for a given support platform displacement, the module first transforms each fairlead position from the global frame to this local system to determine its location relative to the anchor, $x_{F}$ and $z_{F}$.

We take advantage of the analytical formulation for an elastic cable suspended between two points, hanging under its own weight (in fluid). For brevity, the derivation of this analytical formulation is not given here. But we derived it following a procedure similar to that presented in Ref. 15. (The derivation is not exactly the same because Ref. 15 does not account for seabed interaction nor does it account for taut lines where the angle of the line at the anchor is nonzero). The derivation requires that we assume the extensional stiffness of the mooring line, $E A$, is much greater than the hydrostatic pressure at all locations along the line. In the local coordinate system, the analytical formulation is given in terms of two nonlinear equations in two unknowns. The two unknowns are the horizontal and vertical components of the effective tension in the mooring line at the fairlead, $H_{F}$ and $V_{F}$, respectively. [The effective tension is defined as the actual cable (wall) tension plus the hydrostatic pressure.] When no portion of the line rests on the seabed, the analytical formulation is as follows:

$$
\begin{gathered}
x_{F}\left(H_{F}, V_{F}\right)=\frac{H_{F}}{\omega}\left\{\ln \left[\frac{V_{F}}{H_{F}}+\sqrt{1+\left(\frac{V_{F}}{H_{F}}\right)^{2}}\right]-\ln \left[\frac{V_{F}-\omega L}{H_{F}}+\sqrt{1+\left(\frac{V_{F}-\omega L}{H_{F}}\right)^{2}}\right]\right\}+\frac{H_{F} L}{E A} \\
\text { and } \\
z_{F}\left(H_{F}, V_{F}\right)=\frac{H_{F}}{\omega}\left[\sqrt{1+\left(\frac{V_{F}}{H_{F}}\right)^{2}}-\sqrt{1+\left(\frac{V_{F}-\omega L}{H_{F}}\right)^{2}}\right]+\frac{1}{E A}\left(V_{F} L-\frac{\omega L^{2}}{2}\right)
\end{gathered}
$$

This formulation is sometimes cited in terms of the inverse of the hyperbolic sine, that is: $\sinh ^{-1}(x)=\ln \left(x+\sqrt{1+x^{2}}\right)$.

The first terms on the right-hand side of Eq. (2) characterize the arc length of the catenary, projected on the $x$ and $z$ - axes. (Even taut mooring lines have a catenary shaped sag.) The second terms on the right hand side of Eq. (2) represent the horizontal and vertical stretching of the mooring line.

The analytical formulation of two equations in two unknowns is different when a portion of the mooring line adjacent to the anchor rests on the seabed:

$$
\begin{aligned}
x_{F}\left(H_{F}, V_{F}\right)= & L-\frac{V_{F}}{\omega}+\frac{H_{F}}{\omega} \ln \left[\frac{V_{F}}{H_{F}}+\sqrt{1+\left(\frac{V_{F}}{H_{F}}\right)^{2}}\right]+\frac{H_{F} L}{E A} \\
& +\frac{C_{B} \omega}{2 E A}\left[-\left(L-\frac{V_{F}}{\omega}\right)^{2}+\left(L-\frac{V_{F}}{\omega}-\frac{H_{F}}{C_{B} \omega}\right) M A X\left(L-\frac{V_{F}}{\omega}-\frac{H_{F}}{C_{B} \omega}, 0\right)\right]
\end{aligned}
$$




$$
z_{F}\left(H_{F}, V_{F}\right)=\frac{H_{F}}{\omega}\left[\sqrt{1+\left(\frac{V_{F}}{H_{F}}\right)^{2}}-1\right]+\frac{V_{F}^{2}}{2 E A \omega} .
$$

The first two terms on the right-hand side of Eq. (3a) combine to represent the unstretched portion of the mooring line resting on the seabed, $L_{B}$. $\left[L_{B}\right.$ is zero in Eq. (2).] That is:

$$
L_{B}=L-\frac{V_{F}}{\omega} .
$$

The last term on the right-hand side of Eq. (3a), which involves $C_{B}$, corresponds to the stretched portion of the mooring line resting on the seabed that is affected by static friction. The seabed static friction is modeled simply as a drag force per unit length of $C_{B} \omega$. The $M A X$ function is needed to handle cases with and without tension at the anchor. Specifically, the resultant is zero when the anchor tension is positive; that is, the seabed friction is too weak to overcome the horizontal tension in the mooring line. Conversely, the resultant of the MAX function is nonzero when the anchor tension is zero, which happens when a long enough section of cable is lying on the seabed to ensure that the seabed friction entirely overcomes the horizontal tension in the mooring line.

The remaining terms in Eq. (3) are similar in form to, and typify the same information as, the terms in Eq. (2). They are simpler than the terms in Eq. (2) because the catenary is always tangent to the seabed at the point of touchdown.

Our mooring system module uses a Newton-Raphson iteration scheme to solve nonlinear Eq. (2) and Eq. (3) for the fairlead effective tension $\left(H_{F}\right.$ and $\left.V_{F}\right)$, given the line properties $\left(L, \omega, E A\right.$, and $\left.C_{B}\right)$ and the fairlead position relative to the anchor $\left(x_{F}\right.$ and $\left.z_{F}\right)$. The Jacobian in the Newton-Raphson iteration was implemented with the analytical derivatives of Eq. (2) and Eq. (3). Our module uses the values of $H_{F}$ and $V_{F}$ from the previous time step as the initial guess in the next iteration. As the model is being initialized, we use the starting values documented in Ref. 36. Our mooring system module determines which of Eq. (2) or Eq. (3) must be used as part of the solution process. The equations were implemented in a slightly different form than shown to, for example, avoid divisionby-zero problems when $C_{B}$ is zero-valued.

Once the effective tension at the fairlead has been found, determining the horizontal and vertical components of the effective tension in the mooring line at the anchor, $H_{A}$ and $V_{A}$, respectively, is simple. (The blue arrows depicting $H_{A}$ and $V_{A}$ in Fig. 4 are the horizontal and vertical components of the effective line tension at the anchorthey are not the reaction forces at the anchor.) From a balance of external forces on a mooring line, one can easily verify that:

$$
\begin{gathered}
H_{A}=H_{F} \\
\text { and } \\
V_{A}=V_{F}-\omega L,
\end{gathered}
$$

when no portion of the line rests on the seabed, and:

$$
\begin{gathered}
H_{A}=M A X\left(H_{F}-C_{B} \omega L_{B}, 0\right) \\
\text { and } \\
V_{A}=0,
\end{gathered}
$$

when a portion of the line does rest on the seabed. Though they do not affect the dynamic response of the floating wind turbine system, the anchor effective tensions are computed by our mooring system module and become available outputs from the simulation. 
Next, our mooring system module solves for the configuration of, and effective tensions within, the mooring line. Again, the values of these parameters do not affect the dynamic response of the floating wind turbine system, but they are available outputs from the simulation. When no portion of the mooring line rests on the seabed, the equations for the horizontal and vertical distances between the anchor and a given point on the line, $x$ and $z$, and the equation for the effective tension in the line at that point, $T_{e}$, are as follows:

$$
\begin{gathered}
x(s)=\frac{H_{F}}{\omega}\left\{\ln \left[\frac{V_{A}+\omega s}{H_{F}}+\sqrt{1+\left(\frac{V_{A}+\omega s}{H_{F}}\right)^{2}}\right]-\ln \left[\frac{V_{A}}{H_{F}}+\sqrt{1+\left(\frac{V_{A}}{H_{F}}\right)^{2}}\right]\right\}+\frac{H_{F} s}{E A}, \\
z(s)=\frac{H_{F}}{\omega}\left[\sqrt{1+\left(\frac{V_{A}+\omega s}{H_{F}}\right)^{2}}-\sqrt{1+\left(\frac{V_{A}}{H_{F}}\right)^{2}}\right]+\frac{1}{E A}\left(V_{A} s+\frac{\omega s^{2}}{2}\right) \\
\text { and } \\
T_{e}(s)=\sqrt{H_{F}^{2}+\left(V_{A}+\omega s\right)^{2}}
\end{gathered}
$$

where $s$ is the unstretched arc distance along the mooring line from the anchor to the given point. The similarity between Eq. (7) and Eq. (2) should be apparent. Of similarity with Eq. (3), the equations with seabed interaction are more onerous:

$$
\begin{aligned}
& x(s)= \begin{cases}s & \text { for } 0 \leq s \leq L_{B}-\frac{H_{F}}{C_{B} \omega} \\
s+\frac{C_{B} \omega}{2 E A}\left[s^{2}-2\left(L_{B}-\frac{H_{F}}{C_{B} \omega}\right) s+\left(L_{B}-\frac{H_{F}}{C_{B} \omega}\right) \operatorname{MAX}\left(L_{B}-\frac{H_{F}}{C_{B} \omega}, 0\right)\right] & \text { for } L_{B}-\frac{H_{F}}{C_{B} \omega} \leq s \leq L_{B} \\
L_{B}+\frac{H_{F}}{\omega} \ln \left[\frac{\omega\left(s-L_{B}\right)}{H_{F}}+\sqrt{1+\left(\frac{\omega\left(s-L_{B}\right)}{H_{F}}\right)^{2}}\right]+\frac{H_{F} s}{E A} & \text { for } L_{B} \leq s \leq L \\
& +\frac{C_{B} \omega}{2 E A}\left[-L_{B}^{2}+\left(L_{B}-\frac{H_{F}}{C_{B} \omega}\right) \operatorname{MAX}\left(L_{B}-\frac{H_{F}}{C_{B} \omega}, 0\right)\right]\end{cases} \\
& z(s)=\left\{\begin{array}{ll}
0 & \text { for } 0 \leq s \leq L_{B} \\
\frac{H_{F}}{\omega} \ln \left[\sqrt{1+\left(\frac{\omega\left(s-L_{B}\right)}{H_{F}}\right)^{2}}-1\right]+\frac{\omega\left(s-L_{B}\right)^{2}}{2 E A} & \text { for } L_{B} \leq s \leq L
\end{array},\right. \\
& \text { and } \\
& T_{e}(s)=\left\{\begin{array}{ll}
\operatorname{MAX}\left(H_{F}+C_{B} \omega\left(s-L_{B}\right), 0\right) & \text { for } 0 \leq s \leq L_{B} \\
\sqrt{H_{F}^{2}+\left(\omega\left(s-L_{B}\right)\right)^{2}} & \text { for } L_{B} \leq s \leq L
\end{array} .\right.
\end{aligned}
$$


As shown in Fig. 3, the final calculation in our quasi-static mooring system module is to compute the total load on the support from the contribution of all mooring lines. This mooring system restoring load is found by first transforming each fairlead tension from its local mooring line coordinate system to the global frame, then summing up the tensions from all lines.

\section{Wind Turbine and Support Platform Model Descriptions}

To support concept studies aimed at assessing offshore wind technology that is suitable in the deeper waters off the U.S. Offshore Continental Shelf and other offshore sites, the National Renewable Energy Laboratory's (NREL's) National Wind Technology Center (NWTC) has established a set of baseline wind turbine specifications and reference site properties. The wind turbine specification consists of definitions of the aerodynamic, structural, and control system properties. The rating of this turbine is $5 \mathrm{MW}$, which is large by today's standards, but which is assumed to be the minimum rating necessary to make a floating system economical because of the large proportion of the costs in the support platform. Two floating platform concepts were used for this study. The first is a barge with catenary moorings designed by the Department of Naval Architecture and Marine Engineering (NAME) at the Universities of Glasgow and Strathclyde through a contract with ITI Energy. The second is a barge with spread moorings designed by the Massachusetts Institute of Technology (MIT) through a contract with NREL. Barges were chosen because of their simplicity in design, fabrication, and installation.

\section{A. NREL Offshore 5-MW Baseline Wind Turbine}

The 5-MW turbine design used in this study is typical of large, offshore turbines. We obtained some broad design details from the published documents of turbine manufacturers. We used typical, preliminary-design methods to arrive at the details required to build sophisticated models. Table 1 summarizes some of these properties. Greater detail is available elsewhere. ${ }^{37}$

Table 1. Summary of baseline wind turbine properties.

\begin{tabular}{|l|r|}
\hline Rating & $5 \mathrm{MW}$ \\
\hline Wind Regime & IEC 61400-3 (Offshore) Class 1B, Class 6 winds \\
\hline Rotor Orientation & Upwind \\
\hline Control & Variable Speed, Collective Pitch, Active Yaw \\
\hline Rotor, Hub Diameter & $126 \mathrm{~m}, 3 \mathrm{~m}$ \\
\hline Hub Height & $90 \mathrm{~m}$ \\
\hline Rated Rotor, Generator Speed & $12.1 \mathrm{rpm}, 1173.7 \mathrm{rpm}$ \\
\hline Rated Tip Speed & $80 \mathrm{~m} / \mathrm{s}$ \\
\hline Overhang, Shaft Tilt, Precone & $5 \mathrm{~m}, 5^{\circ}, 2.5^{\circ}$ \\
\hline Rotor Mass & $110,000 \mathrm{~kg}$ \\
\hline Nacelle Mass & $240,000 \mathrm{~kg}$ \\
\hline Tower Mass & $347,460 \mathrm{~kg}$ \\
\hline Overall Center of Mass & $(-0.2 \mathrm{~m}, 0.0 \mathrm{~m}, 64.0 \mathrm{~m})$ \\
\hline
\end{tabular}

\section{B. ITI Energy Barge}

We used a preliminary barge design from ITI Energy for some of the verification exercises and for our loads analysis demonstration. Not only is the barge designed to support the NREL offshore 5-MW baseline wind turbine, but it is also a platform for an OWC wave power device. For simplicity in design and fabrication, the barge is square and the wave energy is extracted from a square moonpool located at the center of the barge. This allows the OWC to be located within the tower. To prevent it from drifting, the platform is moored by a system of eight catenary lines, two of which emanate from each corner of the barge. We modeled the slack mooring lines as being parallel to the sides of the barge, so that each pair would be $90^{\circ}$ apart at the corner. We modeled the mooring system configuration in this way to enable comparisons to work done by NAME, although ITI Energy envisions the actual angle to be $45^{\circ}$. Each catenary has roughly $250 \mathrm{~m}$ of line resting on the seabed when the barge is in its neutral position. We provide some details of the barge and mooring system in Table 2 . The concept is documented in much greater detail in Ref. 10. 
Table 2. Summary of ITI Energy barge properties.

\begin{tabular}{|l|r|}
\hline Size $(\mathrm{W} \times \mathrm{L} \times \mathrm{H})$ & $40 \mathrm{~m} \times 40 \mathrm{~m} \times 10 \mathrm{~m}$ \\
\hline Moonpool $(\mathrm{W} \times \mathrm{L} \times \mathrm{H})$ & $10 \mathrm{~m} \times 10 \mathrm{~m} \times 10 \mathrm{~m}$ \\
\hline Draft, Freeboard & $4 \mathrm{~m}, 6 \mathrm{~m}$ \\
\hline Water Displacement & $6,000 \mathrm{~m}^{3}$ \\
\hline Mass, Including Ballast & $5,452,000 \mathrm{~kg}$ \\
\hline Center of Mass (CM) below SWL & $0.323 \mathrm{~m}$ \\
\hline Roll Inertia about CM & $726,900,000 \mathrm{~kg} \cdot \mathrm{m}^{2}$ \\
\hline Pitch Inertia about CM & $726,900,000 \mathrm{~kg} \cdot \mathrm{m}^{2}$ \\
\hline Yaw Inertia about CM & $150 \mathrm{~m}$ \\
\hline Anchor Depth & $834.3 \mathrm{~m}$ \\
\hline Separation Between Opposing Anchors & $473.3 \mathrm{~m}$ \\
\hline Unstretched Line Length & $0.0809 \mathrm{~m}$ \\
\hline Line Diameter & $130.4 \mathrm{~kg} / \mathrm{m}$ \\
\hline Line Mass Density & $589,000,000 \mathrm{~N}$ \\
\hline Line Extensional Stiffness &
\end{tabular}

\section{MIT/NREL Barge}

Elizabeth Wayman of MIT also developed preliminary designs of several floating platforms for the NREL offshore 5-MW baseline wind turbine. One of her designs is named the MIT/NREL shallow drafted barge (SDB). This design is documented in great detail in her M.S. dissertation. ${ }^{9}$ The cylindrical barge has a spread mooring system with four pairs of taut lines radiating outward. We list some of the design specifications in Table 3 .

Table 3. Summary of MIT/NREL barge properties.

\begin{tabular}{|l|r|}
\hline Diameter, Height & $36 \mathrm{~m}, 9.5 \mathrm{~m}$ \\
\hline Draft, Freeboard & $5 \mathrm{~m}, 4.5 \mathrm{~m}$ \\
\hline Water Displacement & $5,089 \mathrm{~m}^{3}$ \\
\hline Mass, Including Ballast & $4,519,000 \mathrm{~kg}$ \\
\hline Center of Mass (CM) below SWL & $3.882 \mathrm{~m}$ \\
\hline Roll Inertia about CM & $390,100,000 \mathrm{~kg} \cdot \mathrm{m}^{2}$ \\
\hline Pitch Inertia about CM & $390,100,000 \mathrm{~kg} \cdot \mathrm{m}^{2}$ \\
\hline Yaw Inertia about CM & $750,900,000 \mathrm{~kg} \cdot \mathrm{m}^{2}$ \\
\hline Anchor Depth & $200 \mathrm{~m}$ \\
\hline Separation Between Opposing Anchors & $436 \mathrm{~m}$ \\
\hline Unstretched Line Length & $279.3 \mathrm{~m}$ \\
\hline Line Diameter & $0.127 \mathrm{~m}$ \\
\hline Line Mass Density & $116.0 \mathrm{~kg} / \mathrm{m}$ \\
\hline Line Extensional Stiffness & $1,500,000,000 \mathrm{~N}$ \\
\hline
\end{tabular}

\section{Verification of Simulation Capability}

The aero-servo-elastic features of FAST and ADAMS have been well verified and validated in previous studies. $^{38-43}$ However, the new hydrodynamics and mooring system modules are novel and require verification to ensure that the response predictions from the fully coupled aero-hydro-servo-elastic capability are accurate. We have performed six verification studies to test the accuracy of the new features: two for the hydrodynamics module, two for the mooring system module, and two for the complete system. The last pair of verification exercises compared the results from our time domain simulation tool with the results from a frequency domain model. Additionally, though not explicitly documented here, the resulting dynamics from the newly added support platform degrees of freedom (DOFs) in FAST also agree well with ADAMS. Some examples of this are presented in section V. All these verification exercises use model-to-model comparisons. The fully coupled simulation tool will be validated later, once experimental data are made available. 


\section{A. Verification of the Hydrodynamics Module}

We performed two verification tests to check the hydrodynamics module. First, we verified that the output from WAMIT, which is used as input to our hydrodynamics module, is similar to that generated by a different radiation/diffraction solver. Second, we verified that the radiation impulse response functions computed within our hydrodynamics module are the same as what is computed with WAMIT's stand-alone frequency-to-time (F2T) conversion utility.

\section{WAMIT Output/Module Input}

We use WAMIT as a preprocessor for generating the hydrodynamic added-mass and damping matrices, $A_{i j}(\omega)$ and $B_{i j}(\omega)$, and wave-excitation force, $X_{i}(\omega, \beta)$, that are inputs to our simulation tool. WAMIT is a code that uses the three-dimensional, numerical panel method to solve the linearized radiation and diffraction problems for the interaction of offshore platforms with surface waves. The hydrodynamic added mass and damping matrices come from the solution of the radiation problem and depend on the water depth, the geometric shape of the support platform, its proximity to the free surface, and its frequency of oscillation in a particular mode of motion. The hydrodynamic wave-excitation force comes from the solution of the diffraction problem and depends on the water depth, the geometric shape of the support platform, its proximity to the free surface, and the frequency and direction of the incident wave. WAMIT ignores the effects of sea current or forward speed on the radiation and diffraction problems, as well as higher order effects. ${ }^{27}$

Since the hydrodynamic solution generated by our simulation tool is only as good as the hydrodynamic inputs, verifying the acceptability of the WAMIT output is beneficial. Consequently, we ran a test to ensure that the WAMIT output is similar to that calculated by a different radiation/diffraction

solver. Data used by NAME when designing the ITI Energy barge were available to make this comparison.

In WAMIT, the barge was modeled with two geometric planes of symmetry with 2400 rectangular panels within a quarter of the body. Consistent with linear

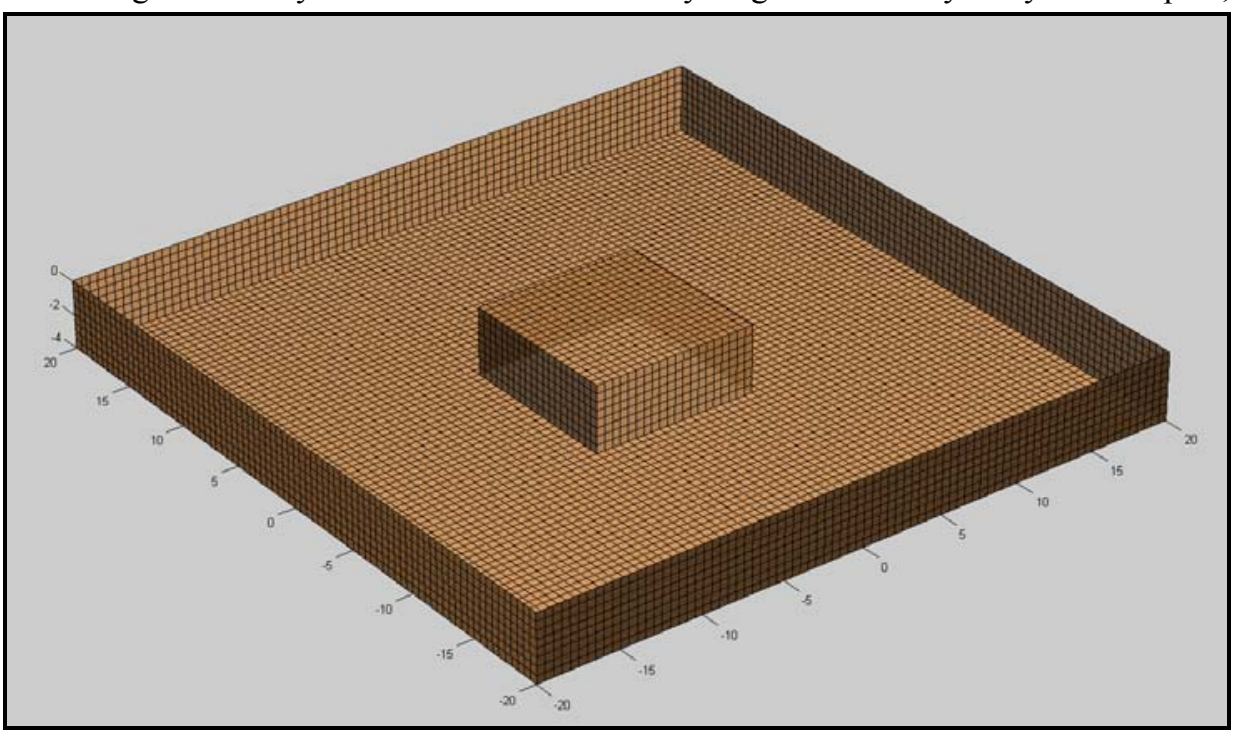

Figure 5. Panel mesh used within WAMIT. theory, we needed to mesh only the wetted portion of the body in its undisplaced position. Figure 5 shows the panel

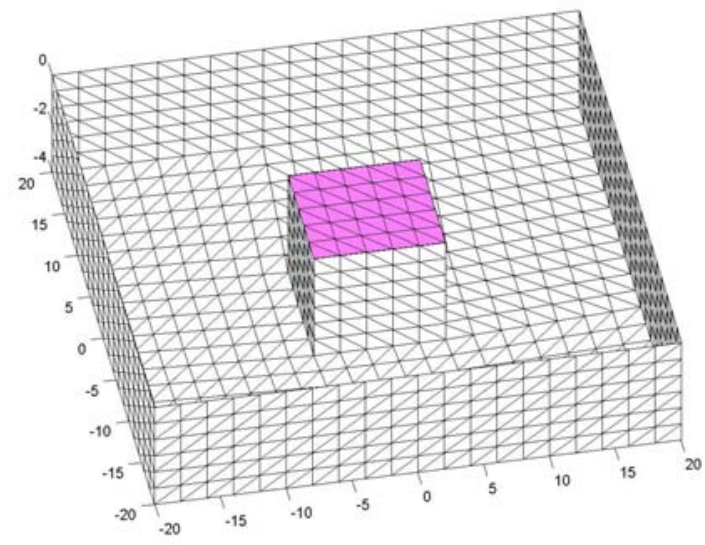

Figure 6. Panel mesh used by NAME. mesh. To avoid accounting for the OWC in the WAMIT analysis, we covered the moonpool with a fixed plate located $0.01 \mathrm{~m}$ below the free surface. In an attempt to model the OWC in NAME's analysis, they considered that the plate was free to move relative to the barge. The panel mesh for NAME's analysis is shown in Fig. 6.

To improve the accuracy of the WAMIT results, we chose to override default settings to (a) integrate the logarithmic singularity analytically, (b) solve the linear system of equations using a direct solver, and (c) remove the effects of irregular frequencies by automatically projecting the body panels to the free surface. These settings were necessary since some panels are located in a plane near the free surface, the barge has a large waterplane area, and high frequency results were needed in subsequent analyses. The barge was analyzed in its undisplaced position with infinite water depth 
in both codes. The hydrodynamic added mass and damping matrices were compared in all six rigid body modes of motion of the barge (in the subscripts, $1=$ surge, $2=$ sway, $3=$ heave, $4=$ roll, $5=$ pitch, $6=$ yaw). As such, the matrices at each frequency are size $6 \times 6$. Since the plate was considered as a separate body in NAME's analysis, the resulting matrices at each were size $12 \times 12$, but these were reduced down to $6 \times 6$ matrices via post-processing to assist in the comparison. The hydrodynamic wave-excitation force was not considered in this test.

Figure 7 shows the results in a side-by-side comparison. All data are dimensional as indicated. Only the uppertriangular matrix elements are shown since the hydrodynamic added mass and damping matrices are symmetric in the absence of sea current or forward speed. ${ }^{14,15}$ Also, because of the barge's symmetries, the surge-surge elements of the frequency-dependent added mass and damping matrices, $A_{11}$ and $B_{11}$, are identical to the sway-sway elements, $A_{22}$ and $B_{22}$. Likewise, the roll-roll elements, $A_{44}$ and $B_{44}$, are identical to the pitch-pitch elements, $A_{55}$ and $B_{55}$. Other matrix elements not shown are zero-valued or very close to being zero-valued.

The WAMIT results are given in even increments of frequency. The NAME results are given in even increments
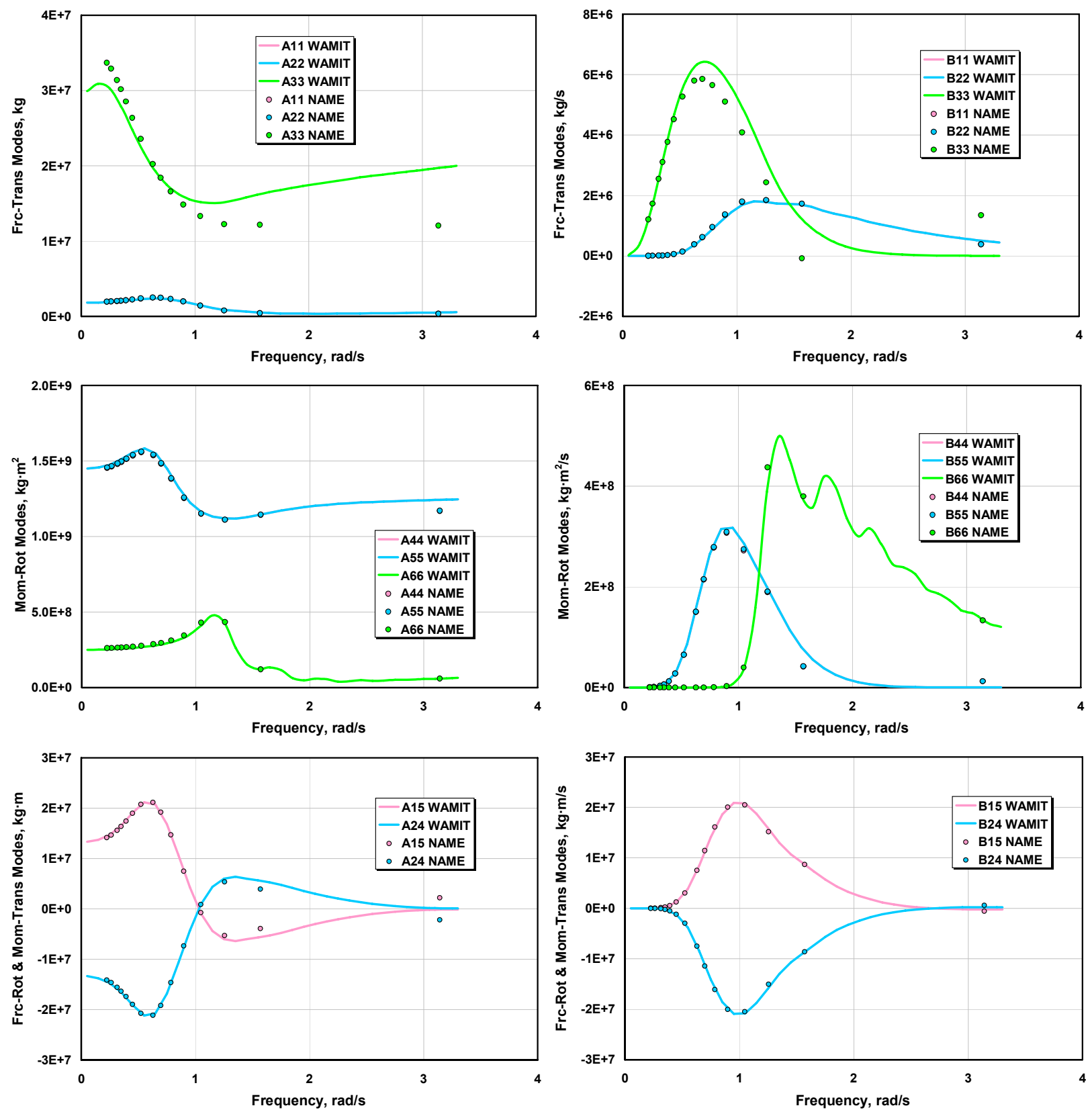

Figure 7. Frequency-dependent hydrodynamic added-mass and damping matrices for the ITI Energy barge. 
of period, so resolution is lost at the higher frequencies. As expected, all matrix elements peak out at some intermediate frequency and level out at higher frequencies. Additionally, the zero- and infinite-frequency limits of all elements of the hydrodynamic damping matrix are zero (not all shown), as required by theory. ${ }^{14,15}$ The comparisons between the output of WAMIT and the results of NAME agree very well, in general, and demonstrate that WAMIT is an acceptable code for generating the hydrodynamics inputs needed by our simulation tool. The biggest discrepancies are in the heave-heave elements of the frequency-dependent added mass and damping, $A_{33}$ and $B_{33}$. We believe that these differences are artifacts of the dissimilar numerical solutions employed by WAMIT and NAME's radiation/diffraction solver. The differences are not large, however, and are not deemed crucial to the accuracy of our hydrodynamics solution.

\section{Computation of Radiation Impulse-Response Functions}

As described in Ref. 20, when a body is forced to move in a fluid, waves are generated on the free surface. As time progresses, these waves will propagate, or radiate away from the body and will influence the fluid pressure on the body for all subsequent time. The resulting time-dependent hydrodynamic loads are known as memory effects, denoting that they depend on the history of motion of the body. The memory effect is captured in our model through the convolution term in Fig. 2. The kernel, $K_{i j}(t)$, in this convolution integral is commonly referred to as the impulse response function of the radiation problem. Specifically, the $(i, j)$ component of the radiation impulse response function, $K_{i j}(t)$, represents the hydrodynamic force at time $t$ in the direction of DOF $i$ due to a unit impulse in velocity at time zero of DOF $j$. In our hydrodynamics module, we used numerical convolution in the time domain to implement the memory effect directly.

Reference 20 also describes how the radiation impulse response functions can be found from the solution of the frequency domain, radiation problem. Specifically, they can be found from either the sine or cosine transform of the frequency-dependent hydrodynamic added mass or damping matrices, respectively. The solution that uses cosine transforms is simpler when the integrals are computed numerically, because without a correction for truncation error, the accuracy of the sine transforms is poor near $t=0$, where $K_{i j}(0)$ is, in general, not zero [even though $\sin (0)$ is]. Since the cosine transform is simpler to compute accurately, our hydrodynamics module uses it to compute the radiation impulse response functions. Nevertheless, verifying that this transform is implemented correctly is still advantageous. The cosine transform in our hydrodynamics module was implemented using a computationally-efficient Fast Fourier Transform (FFT) routine.

We perform the test by verifying that the radiation impulse response functions computed within our hydrodynamics module are the same as what is computed by WAMIT's stand-alone F2T conversion utility. We use the WAMIT output of the frequency-dependent hydrodynamic-damping matrix for the ITI Energy barge from the previous verification test. Because the comparison between F2T and our results is so good, only one set of results is presented, as shown in Fig. 8. As before, all data are dimensional as indicated and, because of the symmetries of the barge, the surge-surge elements are identical to the sway-sway elements and the roll-roll elements are identical to the pitch-pitch elements. Most of the response decays to zero after about $20 \mathrm{~s}$ (as shown) and has all but vanished at $60 \mathrm{~s}$ (not shown). Consequently, when we run our simulation tool, we generally truncate the numerical convolution after $60 \mathrm{~s}$ of memory.

\section{B. Verification of the Mooring System Module}

We also performed two verification tests to check our quasi-static mooring system module. First, we verified that our mooring system module correctly solves a classic benchmark problem for the static equilibrium of a suspended cable structure. Second, we verified that the nonlinear force-displacement relationships for a mooring system in surge, which are computed by our module, are the same as what was calculated by an independent analysis performed by NAME.

\section{Benchmark Problem}

A classical test problem for checking the accuracy of a mooring system program is that of a horizontally suspended cable with one support free to slide laterally. The problem is illustrated in Fig. 9. For a cable of unstretched length, $L=200$, weight per unit length, $\omega=0.1$, extensional stiffness, $E A=10^{5}$, and a horizontal load of $H_{F}=5.77$ applied at the free end (the fairlead), the theoretical, static equilibrium solution is for a horizontal span of, $x_{F}=152.2$, and a vertical sag of 58.0.

This benchmark problem involves finding a static equilibrium position of the fairlead. We tested our mooring system module (in its form without seabed interaction) by solving this problem through time-integration of the nonlinear equations of motion for as long as it took until the solution converged. We had to solve the problem in 

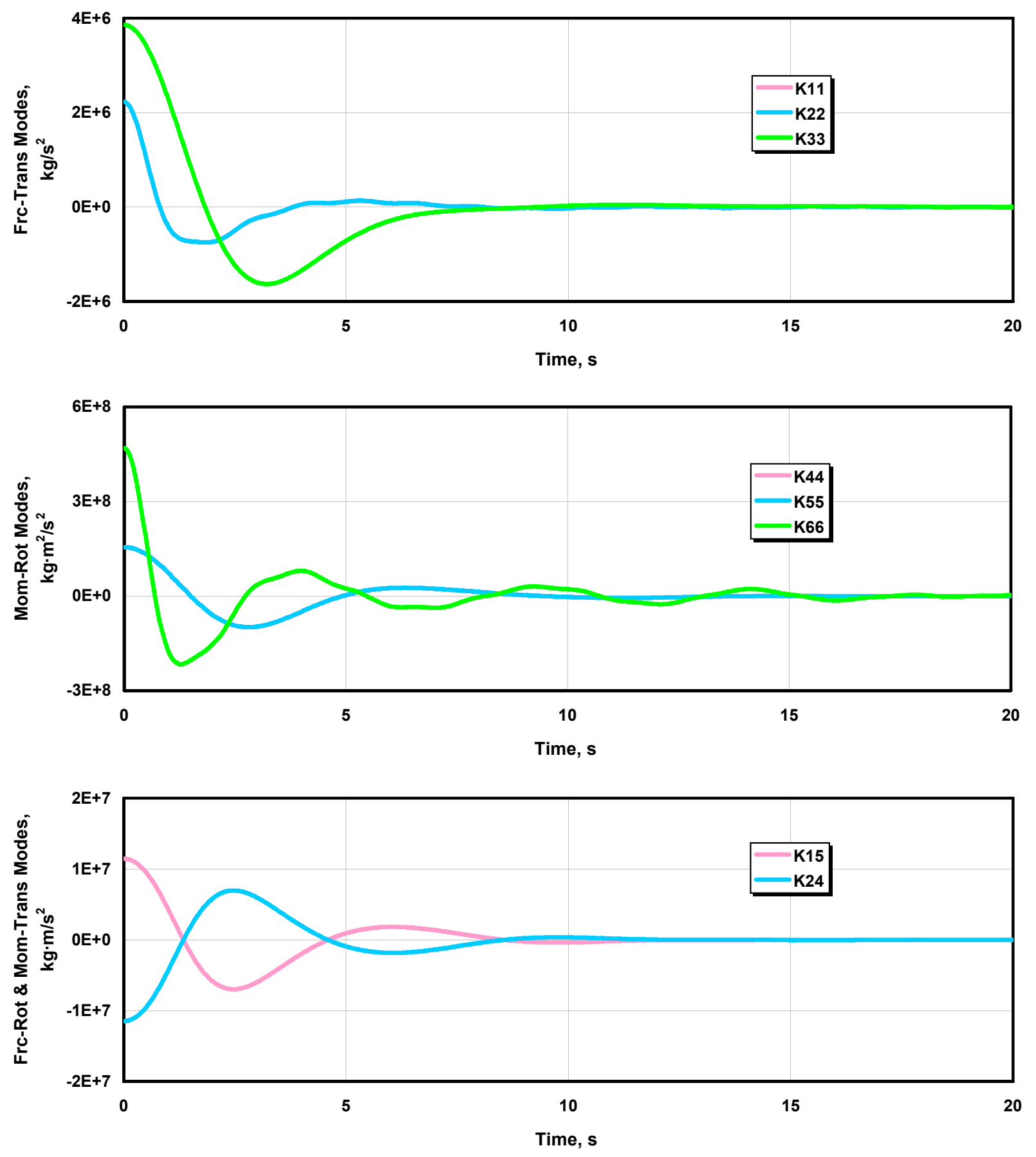

Figure 8. Time-dependent radiation impulse response functions for the ITI Energy barge.

this way because our mooring system module is interfaced to FAST and ADAMS, which both operate in the time domain. The platform, where the fairlead attaches, was given one horizontal translation DOF and a small, inconsequential mass. A small amount of linear damping was added to the motion to ensure that it eventually settled out. If our mooring system module was implemented correctly, the horizontal span and vertical sag should settle out at the correct solution regardless of the lateral offset chosen as an initial condition for the DOF. Indeed, this is exactly what happens.

Figure 10 shows the time series solution when the fairlead was positioned to the left of the anchor at time zero at a lateral offset of -100 . Both FAST and ADAMS gave identical results. The solution is seen to converge to the correct result after about $120 \mathrm{~s}$. Other initial conditions showed similar behavior with the same result. 


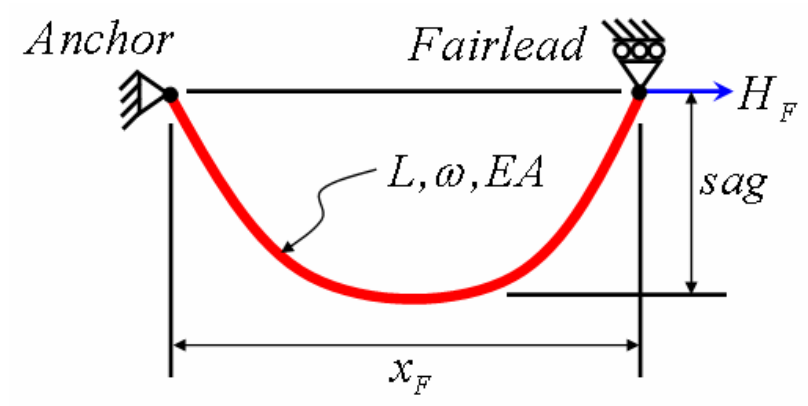

Figure 9. Benchmark problem for a suspended cable.

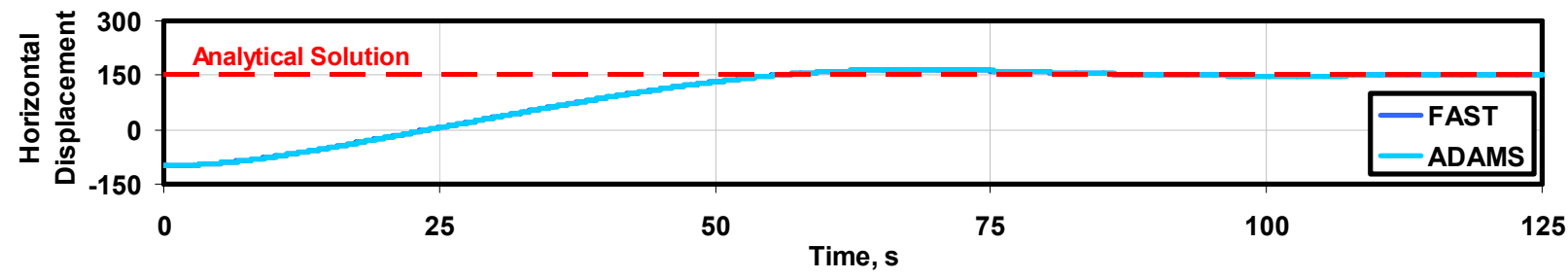

Figure 10. Solution of the suspended cable benchmark problem using our mooring system module.

2. Nonlinear Force-Displacement Relationships

Strong nonlinearities are evident in the force-displacement relationships of most mooring systems. Since these nonlinearities may be important in the dynamic response of floating offshore wind turbines, we must check to ensure that our quasi-static mooring system module is computing them correctly.

NAME used an in-house MathCAD workbook to design the mooring system for the ITI Energy barge. Their model accounts for homogenous taut or catenary lines with elastic horizontal (but not vertical) stretching. A portion of a line may rest on the seabed in NAME's model, but seabed friction was not accounted for. Even though this model was simpler than ours, comparing our results with NAME's enables us to verify our analysis module in its form with seabed interaction.

The layout of the mooring system for the ITI Energy barge is discussed in section IIIB. NAME computed the force-displacement relationships for surge motions of the barge. The relationships were computed for each line independently as well as opposing lines jointly. To reproduce NAME's results, we built a model of the barge and mooring system in ADAMS and translated the barge in surge through a time marching simulation. The timedependent motion of the barge does not affect the results of this analysis, because the mooring lines are treated quasi-statically in our model.

As in previous verification tests, the results from this exercise compare very well. Because the agreement is so good, again, only our set of results is presented, as shown in Fig. 11. There is a horizontal tension of about $100 \mathrm{kN}$

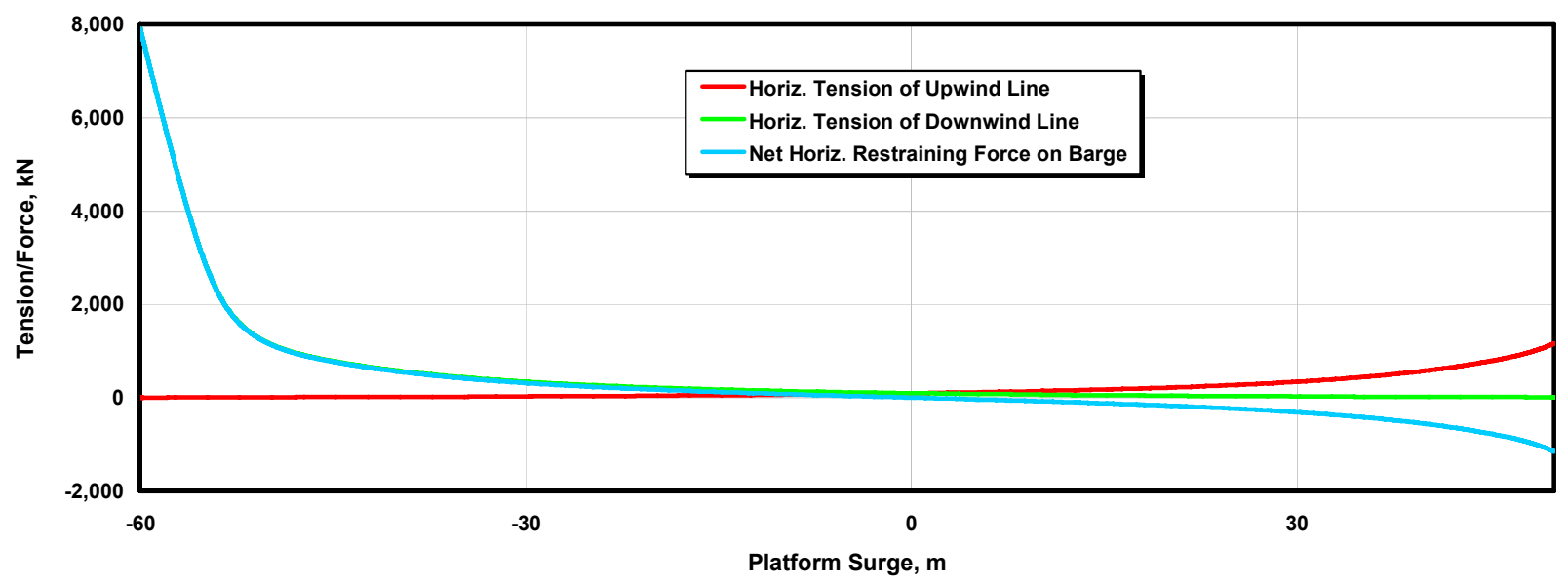

Figure 11. Nonlinear force-displacement relationships for the mooring system of the ITI Energy barge. 
in each line when the barge is in its neutral position. The force-displacement curve for opposing lines, which represents the net horizontal restraining force, remains fairly linear between $+20 \mathrm{~m}$ and $-20 \mathrm{~m}$ of surge motion. Beyond a surge displacement of about $40 \mathrm{~m}$, the resistance of the mooring system increases dramatically. At $50 \mathrm{~m}$ of surge displacement, the horizontal tension in each line is greater than $1,000 \mathrm{kN}$.

\section{Time Domain Versus Frequency Domain Verification}

Since our fully coupled aero-hydro-servo-elastic simulation tool is the first of its kind, finding independent model results to use for verification is difficult. The time domain models that have been developed and used by others in the past for analyzing floating offshore wind turbines ${ }^{11-13}$ were not rigorous enough to provide sufficient verification data. Most of the previous studies on floating offshore wind turbines used frequency domain models. ${ }^{6-10}$ We can use the results of a frequency domain analysis to verify our simulation tool because the hydrodynamic theory in our module was derived from the time domain representation of the frequency domain problem. ${ }^{20}$ Two such verifications are presented.

Frequency domain solutions describe the sinusoidal steady-state response of the support platform, which arise from the interaction of the body with incident waves that propagate at a single amplitude, frequency, and direction. The solution to the frequency domain problem is generally given in terms of RAOs, which are the complex-valued amplitudes of motions for each DOF of the support platform, normalized per unit wave amplitude. Imaginary components indicate that the response is out of phase with the wave elevation. In a time domain model, the sinusoidal steady-state response of a floating offshore wind turbine system can be found by introducing regular, periodic waves as forcing functions, and simulating in time long enough to ensure all transient behavior has died out. As a first verification of our fully coupled model, we used such time series simulations to back-out the RAOs at discrete frequencies. (The process was repeated to find the RAOs at each desired frequency.) We use the frequency domain results for the MIT/NREL SDB presented by Wayman ${ }^{9}$ for this verification test.

In the frequency domain problem, the response of the system to stochastic sea states can only be characterized statistically since the frequency domain representation is not valid for transient analysis. Specifically, the motion of a linearized floating offshore wind turbine system will have a response that is Gaussian distributed when it is excited by a sea state whose instantaneous wave elevation is Gaussian distributed. (Stochastic sea states are, in general, Gaussian distributed.) The standard deviations of the motion response are dictated by the Wiener-Khinchine theorem. ${ }^{9}$ In a time domain model, the distribution of the motion response can be ascertained by post-processing the output of a series of simulations that are long enough to ensure statistical reliability in the results. (The process can be repeated to find the distribution at each desired sea state.) We used this procedure as a second verification of our fully coupled, time domain model, again using the frequency domain results for the MIT/NREL SDB presented by Wayman ${ }^{9}$ for comparison.

For these verification tests, we used the NREL offshore 5-MW baseline wind turbine installed on the MIT/NREL SDB. We chose this configuration and Wayman's frequency domain results because that was the only configuration and only study documented with enough information for us to build a system model and compare results for all six platform modes of motion. Wayman used WAMIT to compute the frequency domain hydrodynamic properties of the MIT/NREL SDB. She modeled the spread mooring system described in section IIIC with linear restoring only in the surge and sway DOFs. She used LINES ${ }^{35}$ to find the linear restoring coefficients of $4 \mathrm{MN} / \mathrm{m}$. The attributes of the wind turbine were included in her linearized system model by augmenting the body mass matrix with the mass properties of the turbine and by augmenting the hydrodynamic damping and restoring matrices with damping and restoring contributions from rotor aerodynamics and gyroscopics. Wayman ignored the elasticity of the wind turbine and considered only the six rigid body modes of the SDB. ${ }^{9}$

1. Verification with Steady-State Response

For this comparison, we constructed a FAST model of the NREL offshore 5-MW baseline wind turbine installed on the MIT/NREL SDB. To ensure reasonable similarity to Wayman's model and to isolate the behavior of the hydrodynamics and mooring system, we modeled the turbine without any DOFs or a control system (only the six rigid body DOFs of the platform were included). For environmental conditions, we used a constant, $11.2-\mathrm{m} / \mathrm{s}$ unsheared wind and regular, periodic waves of unit amplitude (a peak-to-peak height of $2 \mathrm{~m}$ ). Both the wind and waves were codirectional and aligned with the surge coordinate.

When we first attempted to run our time domain simulations, we modeled the spread mooring system with our quasi-static mooring system module interfaced to FAST. However, we soon discovered that the nonlinear restoring of the spread mooring system prohibited the response from ever reaching a sinusoidal steady-state condition, which eliminated any possibility of backing out the RAOs. To get around this, we decided to remove the interface to our mooring module and instead model the mooring system as Wayman did with linear restoring coefficients, only in surge and sway. Thus, the results presented next are not useful for verifying the time domain implementation of our 
mooring system module. However, they are still useful for verifying the time domain implementation of our hydrodynamics module.

With the linearized mooring system model, we ran a series of 2000-s simulations to give them time to reach a periodic steady state. Even after all that time, the platform motion was still not perfectly sinusoidal for the sway, roll, and yaw responses. We ran 10 simulations and varied the discrete frequency of the waves from 0.15 to 1.05 $\mathrm{rad} / \mathrm{s}$ in even increments. Using the last cycle from each simulation, we computed the amplitudes of the oscillations for the three translational and three rotational platform responses. Since our waves were unit amplitude, these response amplitudes were the magnitudes of the RAOs. For the rotational responses, we normalized the RAOs by the platform radius $(18 \mathrm{~m})$, as was done by Wayman. We added our results to the nondimensional RAO plots that Wayman had generated. In these tests, we did not compare the phases of the response.

As seen in Fig. 12, our time domain predictions closely mimic those from Wayman's frequency domain analysis for the platform surge and heave modes. This gives us confidence that our time domain implementation of the
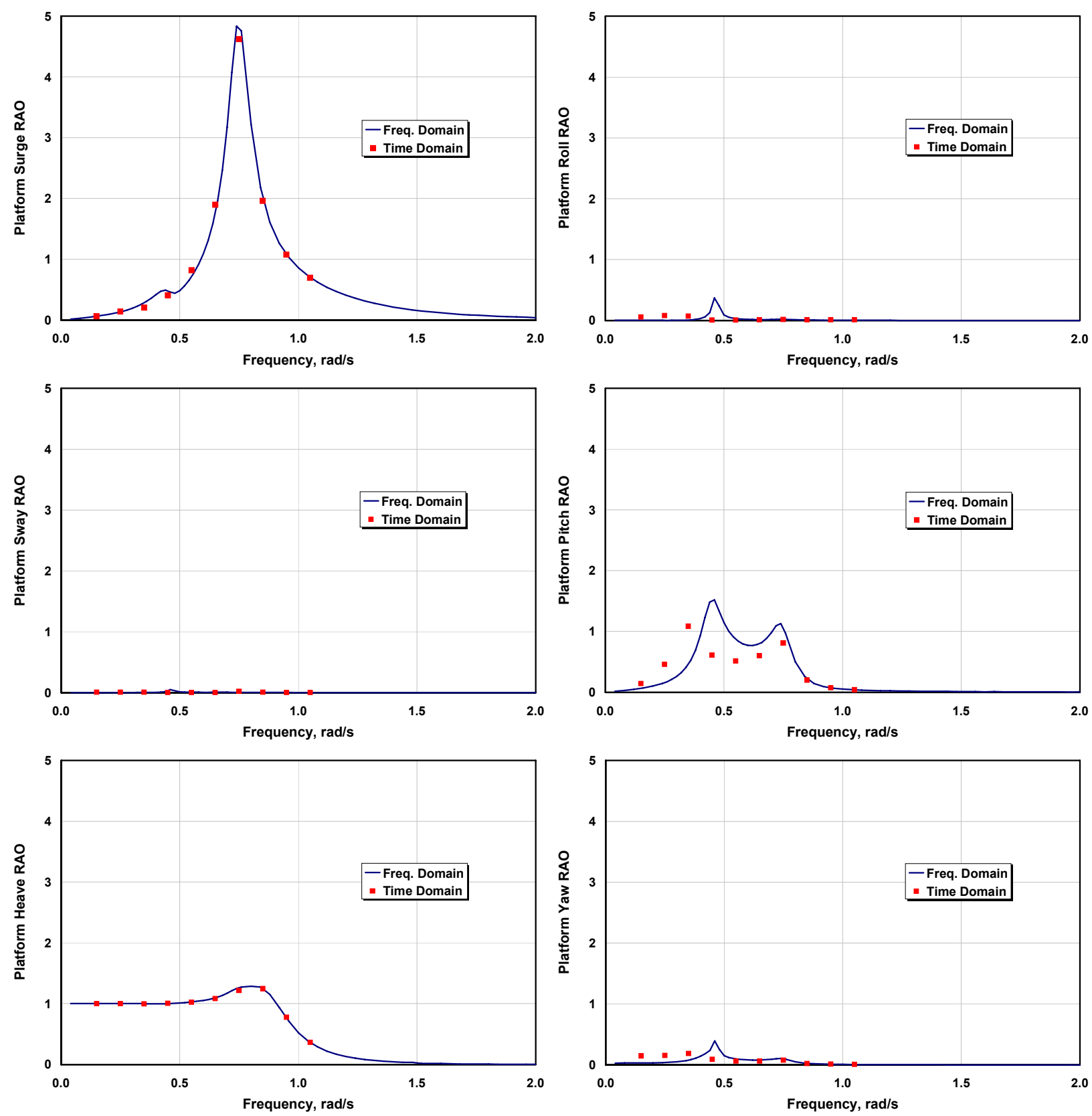

Figure 12. RAO comparisons for the MIT/NREL SDB. 
platform hydrodynamics was correct. The platform pitch curves seem to have a similar character, but portions differ in both magnitude and frequency. The other three parameters - sway, roll, and yaw-have such small responses that comparison is difficult. The fact that the oscillations of these modes had not completely become sinusoidal after $2000 \mathrm{~s}$ brings into question the meaningfulness of those comparisons. Even though there is no excitation of the platform yaw mode from aerodynamics or hydrodynamics in this configuration, the yaw response is nonzero because the spinning inertia of the rotor, combined with the pitching motion of the platform, induces a gyroscopic yaw moment.

We believe that the differences in the pitch RAO are caused by the variation between our models for the aerodynamic damping in pitch. Wayman showed that the platform damping in pitch is completely dominated by rotor aerodynamics, not by wave radiation (see Appendix A.1 of Ref. 9). This is not true for the other modes of motion, such as surge and heave. In Wayman's analysis, the aerodynamic damping in pitch was constant (it was derived by linearizing the rotor aerodynamics about the mean pitch orientation of the platform). In our analysis, the aerodynamic damping in pitch varies as the turbine oscillates against and with the wind.

2. Verification with Stochastic Response

To verify the stochastic response, we built three FAST models of the NREL offshore 5-MW baseline wind turbine installed on the MIT/NREL SDB. The first was the same one used in the RAO comparison: it had a rigid turbine, no control system, and linearized mooring lines in surge and sway. For the second model, we swapped the linearized mooring line model with the standard interface between FAST and our quasi-static mooring system module. To see how well these simpler models agree with higher fidelity simulations, for the third model, we replaced the rigid turbine model with a fully flexible one and enabled the variable-speed generator torque and blade pitch control system.

The published results 9 of Wayman's frequency domain study included mean and standard deviations of the normally distributed responses at a variety of sea states, wind speeds, and water depths. We chose to make a comparison with all three of our models for only one of these cases. The case we chose uses winds roughly at rated $(11.2 \mathrm{~m} / \mathrm{s})$, a water depth of $200 \mathrm{~m}$, and a Pierson-Moskowitz wave spectrum with a significant wave height, $H_{s}$, of $5.49 \mathrm{~m}$ and a mean wave period of $11.3 \mathrm{~s}$, which corresponds to a peak spectral period of about $14.6 \mathrm{~s}$ or a peak spectral frequency of about $0.429 \mathrm{rad} / \mathrm{s}$. We used steady, unsheared winds in the first two models, but for the third model with an active control system, we used turbulent, sheared winds, with a mean hub-height speed of $11.2 \mathrm{~m} / \mathrm{s}$. As before, the wind and waves were codirectional and aligned with the surge coordinate.

For each model, we computed the probability mass densities for all but the first $30 \mathrm{~s}$ of a series of four 10,000-s simulations (just shy of $3 \mathrm{~h}$ each) and used different random seeds for the stochastic waves. We constructed an aggregate of the four cases before computing the probability masses. We plotted our resulting histograms against the Normal probability density functions derived from Wayman's frequency domain analysis. We had to make one correction to the results published by Wayman. ${ }^{9}$ We discovered that when Wayman computed the standard deviations of motion for the rotational modes of the platform, she incorrectly dimensionalized her results. To correct for this mistake, all the standard deviations of motion she presented for the rotational modes must be scaled up by a factor of $\sqrt{180 / \pi}$ to reach the values she meant to publish. The results presented below account for this correction.

Figure 13 presents the comparison between our time domain results and Wayman's frequency domain results. The differences between the results of our second and third models were much smaller than the changes brought about by the switch to nonlinear mooring lines, so only the results from the first and third models are shown. As with the RAOs, the surge and heave predictions for our model with the linearized mooring lines agree very well. The spread for the pitch response is narrower for the FAST simulation with the linearized mooring system than it is in Wayman's predictions. This is consistent with what we saw with the pitch RAO comparison: Wayman's RAO was greater at $0.429 \mathrm{rad} / \mathrm{s}$ than the magnitude predicted by FAST.

After introducing our nonlinear mooring system module in the FAST simulations, the mean surge, pitch, and heave responses decreased considerably as shown. This is because once the lines go taut, the stiffness increases dramatically and the mooring system essentially acts as a four bar linkage. This keeps the platform from rising as high or from traveling as far downwind. The thrust on the rotor tries to pitch the turbine downwind, but the much stiffer upwind lines prevent the upwind end of the barge from lifting so far out of the water; the platform, in turn, is pushed slightly upwind. The spread of values for the sway, roll, and yaw is also much greater for the higher fidelity model than for the simpler model. This is because there is more coupling in the system.

Though not shown, we also developed a histogram for the instantaneous wave elevation record computed by, and output from, our simulation tool. As expected, this histogram is Gaussian distributed with zero mean, and a standard deviation for this test case of $H_{s} / 4=1.37 \mathrm{~m}$. 

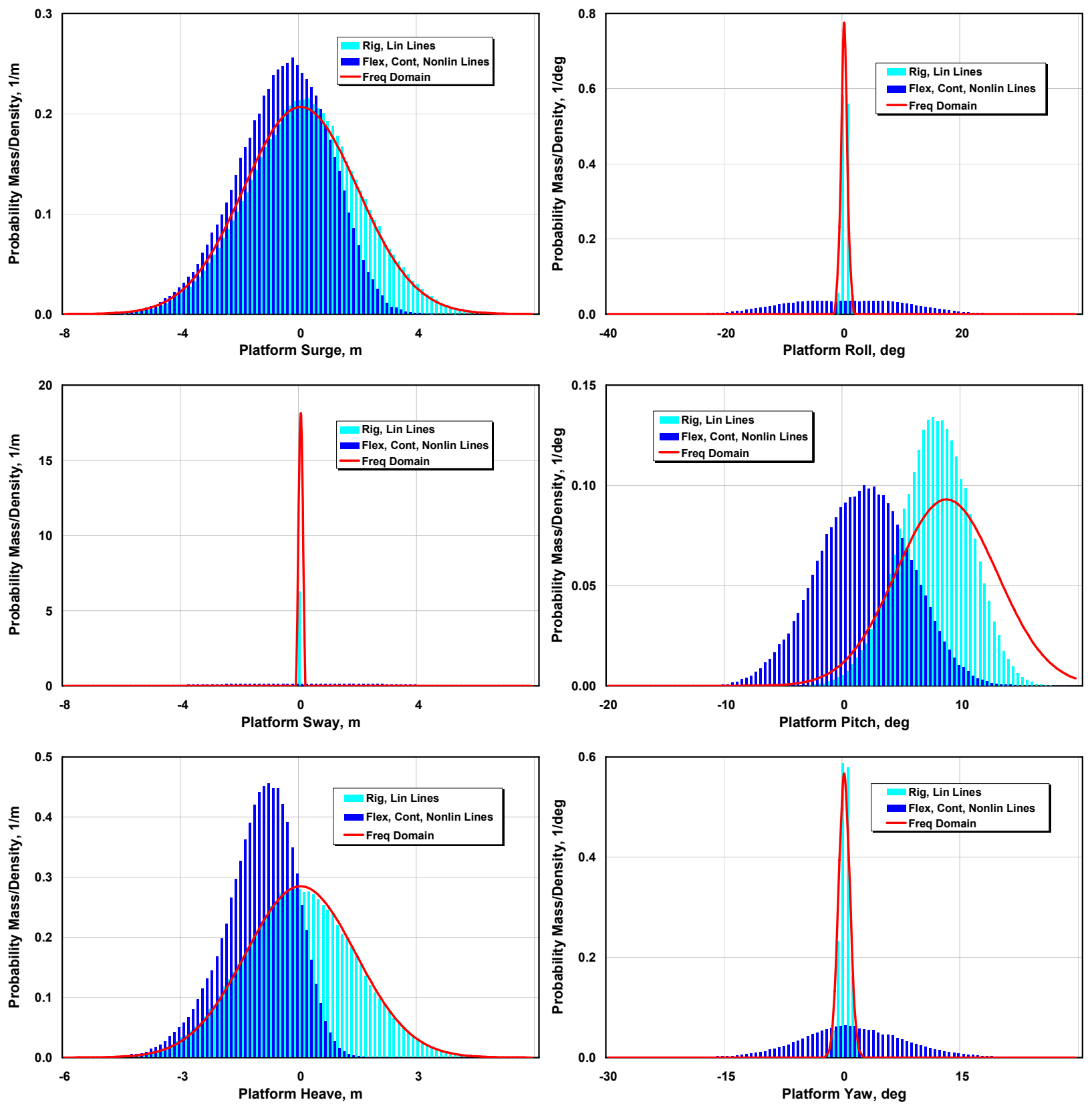

Figure 13. Comparison of frequency domain-generated probability densities to time domain-generated probability masses.

\section{Demonstration of Simulation Capability for Full Coupled Loads Analysis}

To give examples of what can be done with our newly developed simulation capability with regards to loads analysis, we show results from two simulations of the NREL offshore 5-MW baseline turbine mounted on the preliminary ITI Energy barge. The examples demonstrate the capability of our simulation tools, and the potential challenges in the design of floating offshore wind turbines.

As will be shown, there are differences between the FAST and ADAMS predictions. We believe these are mostly caused by the greater fidelity of the ADAMS simulator, which includes torsion and mass offsets in the blades. The blade torsion DOFs allow the blades to twist, which has an effect similar to pitching the outboard portion of the blades. This reduces the amount the blade control system has to pitch the blades. In general, the 
blade pitch values are smaller for ADAMS than for FAST because the control system compensates for the blade twist when regulating speed in Region 3 (above rated).

\section{A. Normal Operation}

The first simulation was for normal operation in $18-\mathrm{m} / \mathrm{s}$ stochastic winds and irregular waves with a $3.3-\mathrm{m}$ significant wave height and an 11.3-s peak spectral period. The incident waves were misaligned with the mean wind direction and nacelle yaw angle by $20^{\circ}$. The first chart of Fig. 14 shows that the waves cause the barge to pitch back and forth. This causes a large translation of the rotor, which results in an oscillating inflow to the wind turbine rotor. As the platform pitches downwind (positive slope), the rotor's relative wind speed decreases, which causes the aerodynamic torque to drop and the control system responds by driving the pitch toward zero. So interestingly, even when the wind speed is significantly above rated, there are still three short periods of Region 2 (below rated) operation. Also, as the aerodynamic torque drops, there is a mismatch with the generator torque, so the rotor speed decreases. The rotor speed is $90^{\circ}$ out of phase with the barge pitch and exhibits much more speed variation than one would see on a land-based wind turbine.

In the second chart of Fig. 14, the tension in the upwind fairlead is lower from FAST than from ADAMS. This is due to the elastic twist DOFs that only the ADAMS model has. Although the control system compensates for the twist by commanding a lower pitch, the control system was not trying to hold the thrust constant. This results in a higher thrust prediction from ADAMS, which then increases the downwind surge of the platform, and also the tension in the upwind fairlead.
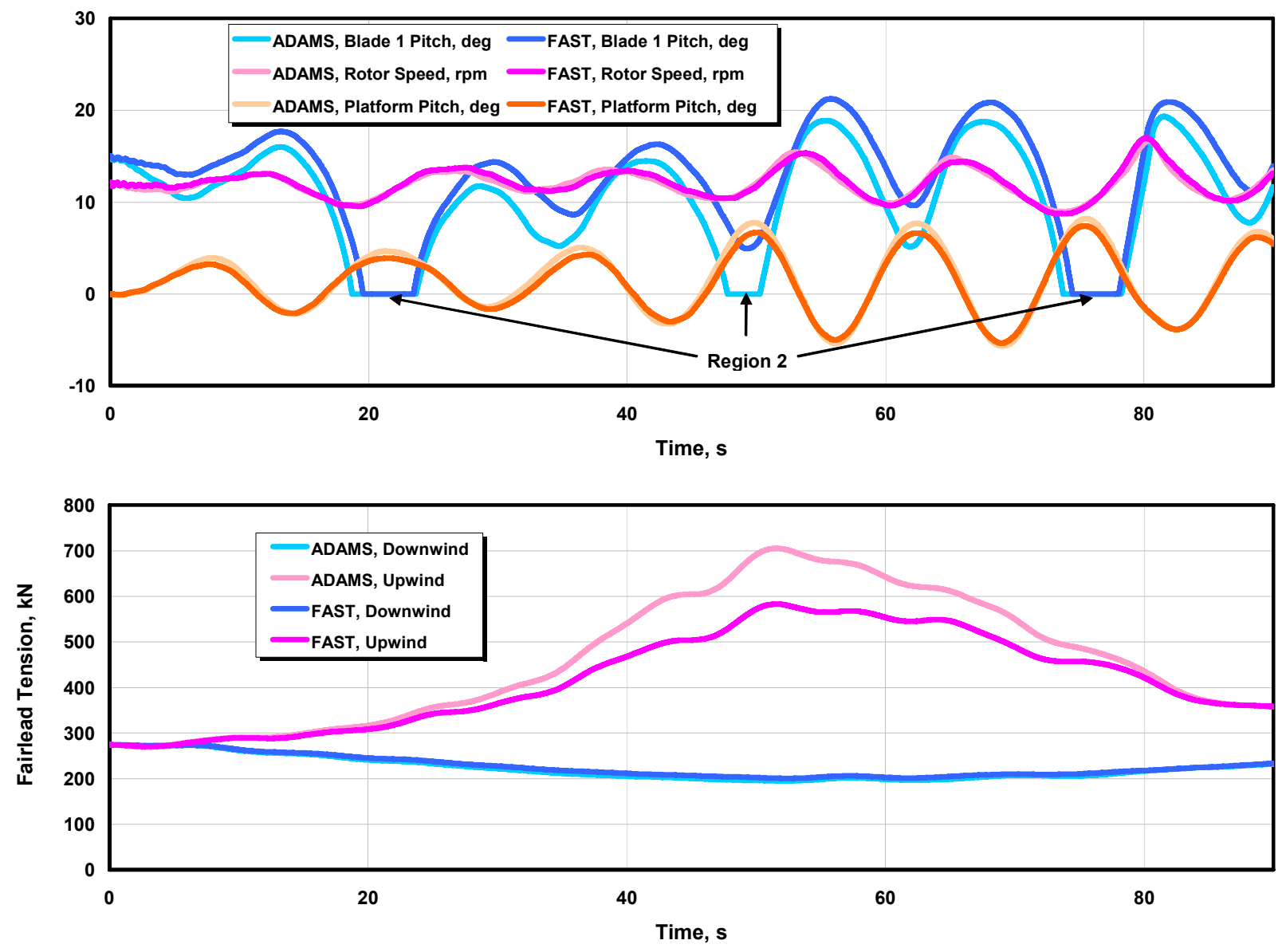

Figure 14. System response during normal operation at $18 \mathrm{~m} / \mathrm{s}$ mean wind speed.

\section{B. Extreme Coherent Gust with Direction Change}

The second simulation was of the International Electrotechnical Commission's (IEC's) standard Extreme Coherent Gust with Direction Change load case. The $15-\mathrm{m} / \mathrm{s}$ gust was added to a steady $10-\mathrm{m} / \mathrm{s}$ wind concurrently 
with a direction change of $72^{\circ}$. The event started at $60 \mathrm{~s}$ and took $10 \mathrm{~s}$ to reach the maximum values, where they remained. We used irregular waves with a significant wave height of $2.1 \mathrm{~m}$ and a peak spectral period of $9.6 \mathrm{~s}$ in this simulation. Before the event, the incident waves were misaligned with the mean wind direction and nacelle yaw angle by $20^{\circ}$, as in the previous example.

We show three charts from this simulation in Fig. 15. Of note is the platform yaw in the middle chart, which shows that the platform begins to yaw slightly into the wind after the wind direction change. There is still a $64^{\circ}$ nacelle yaw error at $90 \mathrm{~s}$ into the simulation, but the mooring lines eventually restrain the platform from yawing any farther. One can also see the phase difference between the FAST and ADAMS results for the oscillating out-of-
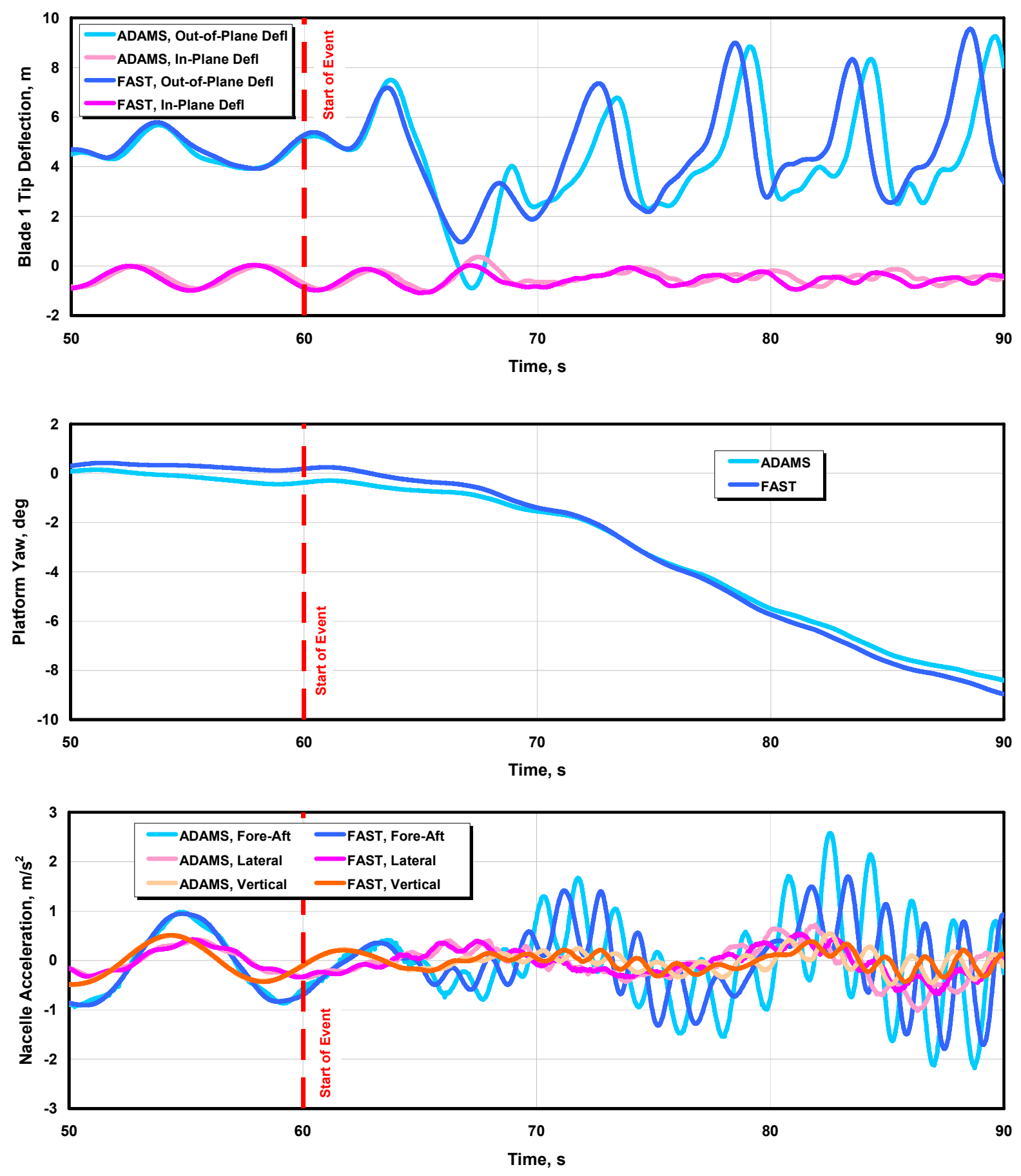

Figure 15. System response during an extreme coherent gust with direction change event. 
plane and in-plane deflection parameters. This shift is likely due to the way ADAMS models the blades differently than FAST. The nacelle acceleration at the main shaft bearing remains within a third of a $g$ during the entire event.

\section{Conclusion}

Limitations of previous time and frequency domain studies on floating offshore wind turbines motivated our development of simulation capability for modeling the fully coupled aero-hydro-servo-elastic response of such systems. This capability has been developed by combining the computational methodologies of the onshore wind turbine and offshore oil and gas industries. The aero-servo-elastic onshore wind turbine simulation capability of FAST and ADAMS with AeroDyn has been interfaced with the hydrodynamic wave-body interaction program WAMIT. This interface has been supported by the development of modules for treating time domain hydrodynamics and quasi-static mooring system responses. To be useful for studying the technical feasibility of multiple floating offshore wind turbine concepts, the developed simulation tool is universal enough to analyze a variety of wind turbine, support platform, and mooring system configurations.

Through model-to-model comparisons, we tested our newly developed simulation capability to ensure its correctness. We showed that WAMIT produces acceptable input for our hydrodynamics module, and from this hydrodynamic input, we showed that our module correctly generates the radiation impulse response functions. We showed that our quasi-static mooring system module correctly solves a classic benchmark problem for the static equilibrium of a suspended cable structure. Moreover, we showed that our mooring system module predicts nonlinear force-displacement relationships consistent with an independent analysis. Finally, the results from our fully coupled time domain analysis were shown to agree with results generated from a frequency domain approach. The results of all of the verification exercises were favorable and give us confidence to pursue more thorough investigations into the behavior of floating offshore wind turbines.

We presented sample simulation results that demonstrate the capability of our simulation tools and highlighted potential challenges to the design of floating offshore wind turbines.

\section{Future Work}

We plan to use the simulation capabilities described in this work to perform loads analyses on a few of the promising floating offshore support platform configurations. Our first loads analysis will be for the NREL offshore 5-MW baseline wind turbine mounted on the ITI Energy barge. The results will help identify critical loads and instabilities brought about, in contrast to onshore wind turbines, by the dynamic couplings between and within the turbine and support platform in the presence of combined wind and wave loading. We will assess the critical loads and instabilities to identify the technical and economic feasibility of the various system concepts and to determine areas where advanced controls development can be used to improve the coupled system dynamic response.

Additional code enhancements to improve the simulation of floating offshore wind turbines are possible. For example, we would like to introduce second-order effects into our hydrodynamics module, including the effects of intermittent wetting and mean-drift, slow-drift, and sum-frequency excitation, which are necessary for accurate modeling of TLP designs and in the analysis of general support platforms subject to large and/or steep waves. We would also like to replace our quasi-static mooring system module with a fully coupled module that can handle the dynamics of the lines. Though not specific to the modeling of offshore wind turbines, we also plan to add a torsion DOF to the modal representation of the tower in FAST and to extend the modal representation of the blades to include mass and elastic offsets, torsion DOFs, and coupled mode shape properties.

\section{Acknowledgments}

We would like to thank everyone who helped with this work, including Elizabeth Wayman of MIT for designing and analyzing the MIT/NREL SDB and Nigel Barltrop and Willem Vijhuizen of NAME for designing and analyzing the ITI Energy barge. We also thank Walt Musial and Sandy Butterfield of NREL for leading the offshore wind energy program there; Jason Jonkman's Ph.D. committee members at the University of Colorado at Boulder, the University of Wyoming, NREL, and MIT for evaluating the project; and Kathleen O'Dell and Stefanie Woodward of NREL, for editing this paper to make it much more readable.

This work was performed at NREL in support of the U.S. Department of Energy under contract number DEAC36-99-GO10337 and in support of a Cooperative Research and Development Agreement with ITI Energy, number CRD-06-178. 


\section{References}

${ }^{1}$ Musial, W.; Butterfield, S.; and Ram, B., "Energy From Offshore Wind," 2006 Offshore Technology Conference, 1-4 May 2006, Houston, TX [CD-ROM], Richardson, TX: Offshore Technology Conference, May 2006, OTC 18355, NREL/CP-50039450.

${ }^{2}$ Musial, W.; Butterfield, S.; and Boone, A., "Feasibility of Floating Platform Systems for Wind Turbines," A Collection of the 2004 ASME Wind Energy Symposium Technical Papers Presented at the $42^{\text {nd }}$ AIAA Aerospace Sciences Meeting and Exhibit, 5-7 January 2004, Reno Nevada, USA, New York: American Institute of Aeronautics and Astronautics, Inc. (AIAA) and American Society of Mechanical Engineers (ASME), January 2004, pp. 476-486, NREL/CP-500-36504.

${ }^{3}$ Watson, G., et al, "A Framework for Offshore Wind Energy Development in the United States," Massachusetts Technology Collaborative (MTC) [online publication], URL: http://www.mtpc.org/offshore/final_09 20.pdf, [cited 17 November 2005].

${ }^{4}$ Musial, W. and Butterfield, S., "Future for Offshore Wind Energy in the United States," EnergyOcean Proceedings, June 2004, Palm Beach Florida, USA, NREL/CP-500-36313.

${ }^{5}$ Butterfield, S.; Musial, W.; Jonkman, J.; Sclavounos, P.; and Wayman, L., "Engineering Challenges for Floating Offshore Wind Turbines," Copenhagen Offshore Wind 2005 Conference and Expedition Proceedings, 26-28 October 2005, Copenhagen, Denmark [CD-ROM], Copenhagen, Denmark: Danish Wind Energy Association, October 2005.

${ }^{6}$ Bulder, B. H., et al, "Study to Feasibility of and Boundary Conditions for Floating Offshore Wind Turbines," Novem 2002CMC-R43, ECN, MARIN, Lagerway the Windmaster, TNO, TUD, MSC, December 2002.

${ }^{7}$ Lee, K. H., "Responses of Floating Wind Turbines to Wind and Wave Excitation," M.S. Dissertation, Department of Ocean Engineering, Massachusetts Institute of Technology, Cambridge, MA, USA, January 2005.

${ }^{8}$ Wayman, E. N.; Sclavounos, P. D.; Butterfield, S.; Jonkman, J.; and Musial, W., "Coupled Dynamic Modeling of Floating Wind Turbine Systems," 2006 Offshore Technology Conference, 1-4 May 2006, Houston, TX [CD-ROM], Richardson, TX: Offshore Technology Conference, May 2006, OTC 18287, NREL/CP-500-39481.

${ }^{9}$ Wayman, E., "Coupled Dynamics and Economic Analysis of Floating Wind Turbine Systems," M.S. Dissertation, Department of Mechanical Engineering, Massachusetts Institute of Technology, Cambridge, MA, USA, June 2006.

${ }^{10}$ Vijfhuizen, W. J. M. J, "Design of a Wind and Wave Power Barge," M.S. Dissertation, Department of Naval Architecture and Mechanical Engineering, Universities of Glasgow and Strathclyde, Glasgow, Scotland, September 2006.

${ }^{11}$ Henderson, A. R. and Patel, M. H., "On the Modelling of a Floating Offshore Wind Turbine," Wind Energy, Vol. 6, No. 1, February 2003, pp. 53-86.

${ }^{12}$ Fulton, G., et al, "Draft Final Report: Semi-Submersible Platform and Anchor Foundation Systems for Wind Turbine Support," NREL Subcontract No. YAM-4-33200-10, Golden, CO: National Renewable Energy Laboratory, July 2005 (to be published).

${ }^{13}$ Withee, J. E., "Fully Coupled Dynamic Analysis of a Floating Wind Turbine System," Ph.D. Dissertation, Department of Ocean Engineering, Massachusetts Institute of Technology, Cambridge, MA, USA, 2004.

${ }^{14}$ Newman, J. N., Marine Hydrodynamics, The MIT Press, Cambridge, MA, USA, 1997.

${ }^{15}$ Faltinsen, O. M., Sea Loads on Ships and Offshore Structures, Cambridge University Press, Cambridge, UK, 1990.

${ }^{16}$ Cummins, W. E., “The Impulse Response Function and Ship Motions,” Schiffstechnik, Vol. 9, October 1962, pp. $101-109$.

${ }^{17}$ Ogilvie, T. F. "Recent Progress toward the Understanding and Prediction of Ship Motions," Fifth Symposium on Naval Hydrodynamics, September, 1964, pp. 3-128.

${ }^{18}$ IEC 61400-1 Ed. 3, Wind Turbines - Part 1: Design Requirements, International Electrotechnical Commission (IEC), 2005.

${ }^{19}$ IEC 61400-3, Wind Turbines - Part 3: Design Requirements for Offshore Wind Turbines, International Electrotechnical Commission (IEC), 2006 (to be published).

${ }^{20}$ Jonkman, J. M. and Sclavounos, P. D., "Development of Fully Coupled Aeroelastic and Hydrodynamic Models for Offshore Wind Turbines," $44^{\text {th }}$ AIAA Aerospace Sciences Meeting and Exhibit, 9-12 January 2006, Reno, NV, AIAA Meeting Papers on Disc [CD-ROM], Reston, VA: American Institute of Aeronautics and Astronautics, January 2006, AIAA-2006-995, NREL/CP-500-39066, Golden, CO: National Renewable Energy Laboratory.

${ }^{21}$ Kühn, M., "Dynamics and Design Optimization of Offshore Wind Energy Conversion Systems," Ph.D. Dissertation, Wind Energy Research Institute, Delft University of Technology, Delft, The Netherlands, 2001.

${ }^{22}$ Passon, P. and Kühn, M., "State-of-the-art and Development Needs of Simulation Codes for Offshore Wind Turbines," Copenhagen Offshore Wind 2005 Conference and Expedition Proceedings, 26-28 October 2005, Copenhagen, Denmark [CDROM], Copenhagen, Denmark: Danish Wind Energy Association, October 2005.

${ }^{23}$ Bossanyi, E. A., "GH Bladed Theory Manual," Issue No. 12, 282/BR/009, Bristol, UK: Garrad Hassan and Partners Limited, December 2003.

${ }^{24}$ Cheng, P. W., "A Reliability Based Design Methodology for Extreme Responses of Offshore Wind Turbines," Ph.D. Dissertation, Wind Energy Research Institute, Delft University of Technology, Delft, The Netherlands, 2002.

${ }^{25}$ Eecen, P. J., "Wind Waves: Forces Due to Waves on Offshore Wind Turbines," ECN-C--03-097, Petten, The Netherlands: Energy Research Centre of The Netherlands, September 2003.

${ }^{26}$ Veldkamp, H. F. and van der Tempel, J., "Influence of Wave Modeling on the Prediction of Fatigue for Offshore Wind Turbines," Wind Energy, Vol. 8, No. 1, January/March 2005, pp. 49-65.

${ }^{27}$ Lee, C. H. and Newman, J. N., "WAMIT ${ }^{\circledR}$ User Manual, Versions 6.3, 6.3PC, 6.3S, 6.3S-PC," WAMIT, Inc., Chestnut Hill, MA, USA, 2006. 
${ }^{28}$ Laino, D. J. and Hansen, A. C., "User's Guide to the Wind Turbine Dynamics Aerodynamics Computer Software AeroDyn," Salt Lake City, UT: Windward Engineering LLC, Prepared for the National Renewable Energy Laboratory under Subcontract No. TCX-9-29209-01, December 2002.

${ }^{29}$ Jonkman, J. M. and Buhl, M. L., Jr., “FAST User's Guide,” NREL/EL-500-29798, Golden, CO: National Renewable Energy Laboratory, October 2004.

${ }^{30}$ Laino, D. J. and Hansen, A. C., "User's Guide to the Computer Software Routines AeroDyn Interface for ADAMS ${ }^{\circledR}$," Salt Lake City, UT: Windward Engineering LLC, Prepared for the National Renewable Energy Laboratory under Subcontract No. TCX-9-29209-01, September 2001.

${ }^{31}$ Elliott, A. S., “Analyzing Rotor Dynamics with a General-Purpose Code,” Mechanical Engineering, Vol. 112, No. 12, December 1990, pp. 21-25.

${ }^{32}$ Kim, S. and Sclavounos, P. D., "Fully Coupled Response Simulations of Theme Offshore Structures in Water Depths of Up to 10,000 Feet," Proceedings of the Eleventh International Offshore and Polar Engineering Conference, 17-22 June 2001, Stavanger, Norway, The International Society of Offshore and Polar Engineers, 2001.

${ }^{33}$ Kim, S., "SWIM 2001: Frequency-Domain Analysis of Offshore Platforms, User Manual," Massachusetts Institute of Technology, Cambridge, MA, USA, 2004.

${ }^{34}$ Kim, S., "MOTION 2001: Time-Domain Response Analysis of Offshore Platforms, User Manual," Massachusetts Institute of Technology, Cambridge, MA, USA, 2004.

${ }^{35}$ Kim, S," "LINES 2001: Nonlinear Static \& Dynamic Analysis of Mooring Line/Riser/Tether Arrays, User Manual," Massachusetts Institute of Technology, Cambridge, MA, USA, 2004.

${ }^{36}$ Peyrot, A. H. and Goulois, A. M., "Analysis of Cable Structures," Computers \& Structures, Vol. 10, 1979, pp. 805-813.

${ }^{37}$ Jonkman, J.; Butterfield, S.; Musial, W.; and Scott, G., "Definition of a 5-MW Reference Wind Turbine for Offshore System Development," NREL/TP-500-38060, Golden, CO: National Renewable Energy Laboratory, January 2006 (to be published).

${ }^{38}$ Buhl, M. L., Jr.; Wright, A. D.; and Tangler, J. L, "Wind Turbine Design Codes: A Preliminary Comparison of the Aerodynamics," NREL/CP-500-23975, Golden, CO: National Renewable Energy Laboratory, 11 pp, December 1997.

${ }^{39}$ Buhl, M. L., Jr.; Wright, A. D.; and Pierce, K. G., "Wind Turbine Design Codes: A Comparison of the Structural Response," Collection of the 2000 ASME Wind Energy Symposium Technical Papers at the $38^{\text {th }}$ AIAA Aerospace Sciences Meeting and Exhibit, 10-13 January 2000, Reno, NV, New York: American Institute of Aeronautics and Astronautics, Inc. (AIAA) and American Society of Mechanical Engineers (ASME); pp. 12-22, NREL/CP-500-27470, Golden, CO: National Renewable Energy Laboratory.

${ }^{40}$ Buhl, M. L., Jr.; Wright, A. D.; and Pierce, K. G. "FAST_AD Code Verification: A Comparison to ADAMS," Collection of the 2001 ASME Wind Energy Symposium Technical Papers at the 39 $9^{\text {th }}$ AIAA Aerospace Sciences Meeting and Exhibit, 11-14 January 2001, Reno, NV, New York: American Institute of Aeronautics and Astronautics, Inc. (AIAA) and American Society of Mechanical Engineers (ASME); pp. 368-377, NREL/CP-500-28848, Golden, CO: National Renewable Energy Laboratory.

${ }^{41}$ Jonkman, J. M., "Modeling of the UAE Wind Turbine for Refinement of FAST_AD," M.S. Dissertation, Department of Mechanical Engineering, Colorado State University, Fort Collins, CO, USA, November 2001; NREL/TP-500-34755, Golden, CO: National Renewable Energy Laboratory.

${ }^{42}$ Majock, A. "Evaluation Report: Design Codes FAST and ADAMS ${ }^{\circledR}$ for Load Calculations of Onshore Wind Turbines," Report No. 72042, Hamburg, Germany: Germanischer Lloyd WindEnergie GmbH, May 26, 2005.

${ }^{43}$ Buhl, M. L., Jr. and Manjock, A., "A Comparison of Wind Turbine Aeroelastic Codes Used for Certification," $44^{\text {th }}$ AIAA Aerospace Sciences Meeting and Exhibit, 9-12 January 2006, Reno, NV, AIAA Meeting Papers on Disc [CD-ROM], Reston, VA: American Institute of Aeronautics and Astronautics, January 2006, AIAA-2006-786, NREL/CP-500-39113, Golden, CO: National Renewable Energy Laboratory.

${ }^{44}$ Underwood, P. G., "Dynamic Relaxation,” Computational Methods for Transient Analysis, Vol. 1, 1983, pp. $245-265$. 


\section{REPORT DOCUMENTATION PAGE}

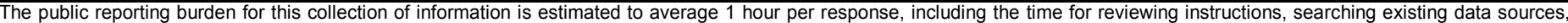

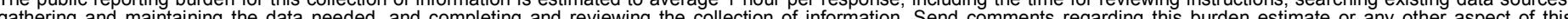

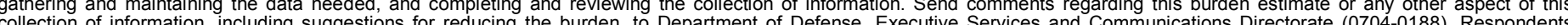

chould be aware that notwithstanding any other provision of law, no person shall be subject to any pena

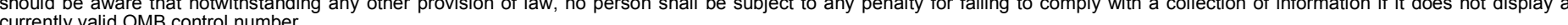

PLEASE DO NOT RETURN YOUR FORM TO THE ABOVE ORGANIZATION.

\begin{tabular}{l|l|l|l} 
1. REPORT DATE $(D D-M M-Y Y Y Y)$ & 2. & REPORT TYPE & 3. DATES COVERED (FrOm - TO)
\end{tabular}

January 2007

Conference paper

4. TITLE AND SUBTITLE

Development and Verification of a Fully Coupled Simulator for

Offshore Wind Turbines: Preprint 5a. CONTRACT NUMBER

DE-AC36-99-G010337

5b. GRANT NUMBER

5c. PROGRAM ELEMENT NUMBER

5d. PROJECT NUMBER

NREL/CP-500-40979

5e. TASK NUMBER

WER7.2902

5f. WORK UNIT NUMBER
7. PERFORMING ORGANIZATION NAME(S) AND ADDRESS(ES)

National Renewable Energy Laboratory

1617 Cole Blvd.

Golden, CO 80401-3393
8. PERFORMING ORGANIZATION REPORT NUMBER

NREL/CP-500-40979

9. SPONSORING/MONITORING AGENCY NAME(S) AND ADDRESS(ES)

10. SPONSOR/MONITOR'S ACRONYM(S) NREL

11. SPONSORING/MONITORING AGENCY REPORT NUMBER

12. DISTRIBUTION AVAILABILITY STATEMENT

National Technical Information Service

U.S. Department of Commerce

5285 Port Royal Road

Springfield, VA 22161

13. SUPPLEMENTARY NOTES

14. ABSTRACT (Maximum 200 Words)

This report outlines the development of an analysis tool capable of analyzing a variety of wind turbine, support platform, and mooring system configurations. The simulation capability was tested by model-to-model comparisons to ensure its correctness.

15. SUBJECT TERMS

wind energy; offshore wind turbines; simulation tools; computer modeling tools

\begin{tabular}{l}
\hline \multicolumn{3}{|l|}{ 16. SECURITY CLASSIFICATION OF: } \\
\hline \begin{tabular}{l|l|l|} 
a. REPORT & b. ABSTRACT & c. THIS PAGE \\
Unclassified & Unclassified & Unclassified \\
& & \\
\hline
\end{tabular} \\
\hline
\end{tabular}

\begin{tabular}{|c|c|} 
17. LIMITATION & 18. \\
OF ABSTRACT & OF PAGES \\
UL &
\end{tabular}

19a. NAME OF RESPONSIBLE PERSON

19b. TELEPHONE NUMBER (Include area code) 